\title{
Peertechz
}

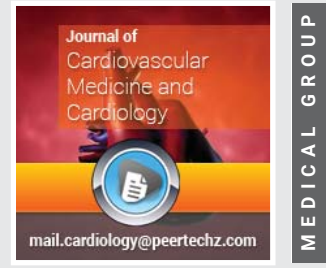

Review Article

\section{Cardiac involvement in}

\section{sarcoidosis: Evolving concepts} in diagnosis and treatment

\section{Joseph P Lynch III ${ }^{*}$, Michael C Fishbein ${ }^{2}$, Jason S Bradfield $^{3}$ and John A Belperio ${ }^{1}$}

${ }^{1}$ The Division of Pulmonary and Critical Care Medicine, Clinical Immunology, Allergy and Sleep,

Department of Medicine, David Geffen School of Medicine at UCLA, Los Angeles, CA, USA

${ }^{2}$ Department of Pathology and Laboratory Medicine, David Geffen School of Medicine at UCLA, Los Angeles, CA, USA

${ }^{3}$ Division of Cardiology, UCLA Cardiac Arrhythmia Center, Department of Medicine, David Geffen

School of Medicine at UCLA, Los Angeles, CA, USA
Received: 17 November, 2021

Accepted: 07 December, 2021

Published: 09 December, 2021

*Corresponding author: Joseph P Lynch III, MD, The Division of Pulmonary and Critical Care Medicine, Clinical Immunology, Allergy and Sleep, Department of Medicine, David Geffen School of Medicine at UCLA, 10833 Le Conte Ave, Room 37-131 CHS, Los Angeles, CA 90095, USA, E-mail: jplynch@mednet.ucla.edu

Keywords: Sarcoidosis; Cardiac; Ventricular arrhythmias; Atrioventricular block; Cardiomyopathy; Implantable Cardioverter-Defibrillator (ICD); Cardiac Magnetic Resonance (CMR); Positron Emission Tomography (PET)

Copyright License: (c) 2021 Lynch III JP, et al. This is an open-access article distributed under the terms of the Creative Commons Attribution License, which permits unrestricted use, distribution, and reproduction in any medium, provided the original author and source are credited.

https://www.peertechzpublications.com

\section{Check for updates}

\begin{abstract}
Clinically evident cardiac involvement has been noted in at least 2 to $7 \%$ of patients with sarcoidosis, but occult involvement is much higher (> 20\%). Cardiac Sarcoidosis (CS) is often not recognized as an antemortem, as sudden death may be the presenting feature. Cardiac involvement may occur at any point during the course of sarcoidosis and may occur in the absence of pulmonary or systemic involvement. Sarcoidosis can involve any part of the heart. The prognosis of CS is related to the extent and site(s) of involvement. Most deaths due to CS are due to arrhythmias or conduction defects, but granulomatous infiltration of the myocardium may cause progressive and ultimately lethal cardiomyopathy. The definitive diagnosis of isolated CS is difficult and the yield of Endomyocardial Biopsies (EMB) is low. Treatment of CS is often warranted even in the absence of histologic proof. Radionuclide scans are integral to the diagnosis. Gadolinium-enhanced cardiac magnetic imaging scans and ${ }^{18}$ Fluorodeoxyglucose $\left({ }^{18} \mathrm{FDG}\right)$-Positron Emission Tomography (PET) are the key imaging modalities to diagnose CS. The prognosis of CS is variable, but mortality rates of untreated CS are high. Randomized therapeutic trials have not been done, but corticosteroids (alone or combined with additional immunosuppressive agents) are the mainstay of therapy. Additionally, anti-arrhythmic agents and therapy for heart failure are often required. Because of the potential for sudden cardiac death, an Implantable Cardioverter-Defibrillator (ICD) should be placed in any patient with CS and serious ventricular arrhythmias or heart block and should be considered for cardiomyopathy. Cardiac transplantation is a viable option for patients with end-stage CS refractory to medical therapy.
\end{abstract}

\section{Abbreviations}

ADA: Adalimumab; ACE: Adverse Cardiac Events; AAA: Anti-Arrhythmic Agents; AFIP: Armed Forces Institute of Pathology; ARVC: Arrhythmogenic Right Ventricular Cardiomyopathy; AF: Atrial Fibrillation; AV: Atrioventricular; AVB: AV Block; BNP: Brain Natriuretic Peptide; BBB: Bundle Branch Block; CMR: Cardiac Magnetic Resonance; CS: Cardiac Sarcoidosis; CHB: Complete Heart Block; CHF: Congestive Heart Failure; CYC: Cyclophosphamide; DMARA: Disease Modifying Anti-Rheumatic Agents; ECG: Electrocardiogram; EMB: Endomyocardial Biopsies; ${ }^{18} \mathrm{FDG}:{ }^{18} \mathrm{~F}$-fluorodeoxyglucose; Gd: Gadolinium; Ga ${ }^{67}$ : Gallium ${ }^{67}$; GCM: Giant Cell Myocarditis;
HR: Hazard Ratio; HB: Heart Block; HF: Heart Failure; IDC: Idiopathic Dilated Cardiomyopathy; ICD: Implantable Cardioverter Debrillator; IFX: Infliximab; IVS: Interventricular Septum; IC: Ischemic Cardiomyopathy; LGE: Late Gadolinium Enhancement; LAE: Left Atrial Enlargement; LV: Left Ventricle; LVEF: Left Ventricular Ejection Fraction; LS: Lofgren's Syndrome; SUV max: Myocardial Maximum Standardized Uptake of ${ }^{18}$ FDG; NHLBI: National Heart Lung Blood Institute; NNG: Non-Necrotizing Granulomas; NSVT: Non-Sustained VT; OR: Odds Ratio; PET: Positron Emission Tomography; PVCs: Premature Ventricular Contractions; PES: Programmed Electric Stimulation; pro-NT-BNP: pro-N-Terminus Brain Natriuretic Protein; RV: Right Ventricle; RVEF: Right Ventricular Ejection 
Fraction; SACE: Serum Angiotensin Converting Enzyme; SA: Sinoatrial Node; SCD: Sudden Cardiac Death; SMVT: Sustained Monomorphic VT; SVT: Sustained VT; Tl201: Thallium201; TTE: Transthoracic Echocardiogram; TB: Tuberculosis; 2D-ST: TwoDimensional Tracking; UK: United Kingdom; UNOS: United Network for Organ Sharing; VA: Ventricular Arrhythmias; LVEF: Ventricular Ejection Fraction; VF: Ventricular Fibrillation; VT: ventricular tachycardia; WASOG: World Association of Sarcoidosis and Other Granulomatous Disorders

\section{Introduction}

In 2017 we reviewed Cardiac Sarcoidosis (CS) in-depth [1] but many studies since that publication have refined the role of radionuclide diagnostic techniques and provided additional therapeutic approaches for CS. Nonetheless, optimal management (diagnosis and therapy) remains controversial. In this review, we first describe multiple sentinel studies in the 1970s through 2000s and update recent findings and advances in the field.

Clinically evident sarcoidosis involving the heart has been noted in at least 2 to $7 \%$ of patients with sarcoidosis [2-5] but occult involvement is much higher (>20\%) $[1,6,7]$. Sudden Cardiac Death (SCD) may be the presenting feature of CS [814] and may occur in the absence of extra-cardiac involvement $[13,15,16]$. Corticosteroids (steroids) have been the mainstay of therapy for CS for more than 50 years [13,17-22], but randomized, placebo-controlled trials have not been done, in large part due to the rarity of CS and potential for severe adverse outcomes (including death) in untreated patients $[9,13]$. As will be discussed in detail later, steroids have been associated with favorable responses in large retrospective trials of CS [23-25] but failures or relapses have led to the use of Immunosuppressive Agents (IA) [26], usually in addition to steroids [27-29]. Further, given the possible role of tumor necrosis factor-a (TNF- $\alpha)$ in the pathogenesis of sarcoidosis [30], TNF $-\alpha$ antagonists have been used to treat CS, usually in cases failing steroids or other IA [31-34]. However, data regarding the use of $(\mathrm{TNF}-\alpha)$ antagonists are even more limited than steroids or IA. Given the lack of randomized trials, optimal therapy of CS is controversial. Additionally, the optimal staging has not been clarified, as diagnostic modalities (principally radionuclide scans) have changed within the past several years. Currently, Positron Emission Tomography (PET) [35-39] and magnetic resonance imaging (IMR) [40-42] are considered the most useful and specific imaging techniques to diagnose and follow CS, but data are limited. Radionuclide techniques are exceptionally expensive and indications for their use, and appropriate guidelines to follow the course of CS have not been established. In this manuscript, we address all of these issues, even though the optimal approach remains to be determined.

\section{Incidence of cardiac involvement in sarcoidosis}

The incidence and prevalence of sarcoidosis (both cardiac and non-cardiac) are markedly different according to racial, ethnic, gender, age, and geographic factors and may vary over time [43]. Sarcoidosis (both cardiac and extra-cardiac) is more common in Blacks [44] and has a higher mortality rate in Blacks than Caucasians [45]. Sarcoidosis is much more common in northern European countries (particularly Scandinavia) and the British Isles and Ireland, but is rare in southern Europe, Central, and South America, Israel, and East Asia [43]. Estimated incidence rates (per 100,000) of sarcoidosis have been reported as follows: USA (17.8, African Americans); 8.1 (whites); 4.3 (Hispanics); 3.2 (Asians) [46]; Sweden 21.7 (women); 16.5 (men) [47]; Finland (11.4) [43]; Denmark (6.48.4) [48]; United Kingdom and Ireland (5.0) [49]; Spain (0.4) [50]; Poland (5.0) and Hungary (3.4) [43]; South Croatia (3.3) [51]; Israel (0.8) [52]; Korea (0.03-0.125 [53]; Singapore (0.56) [54] , Japan (1.01) [55].

Compared to other ethnicities, the incidence of CS is much higher in Japanese individuals with sarcoidosis and is associated with a higher mortality $[13,18,56-58]$. In Japan, cardiac involvement is the leading cause of death due to sarcoidosis, accounting for 77 to $85 \%$ of deaths [13,59]. By contrast, in the United States, 13 to $50 \%$ of sarcoid deaths have been attributed to cardiac involvement $[8,60]$.

Several necropsy series in the USA and United Kingdom (UK) cited pathological evidence for cardiac involvement in $19.5 \%$ to $28 \%$ of patients with sarcoidosis $[9,10,61-63]$.

\section{Genetics of cardiac sarcoidosis}

The increased frequency of cardiac involvement in Japanese patients with sarcoidosis strongly suggests genetic influence $[57,58,64,65]$, but the specific genes responsible for sarcoidosis have not been elucidated [64]. The genetics of sarcoidosis (cardiac and non-cardiac) are exceptionally complex [66] and are beyond the scope of this manuscript.

\section{Pathology and sites of involvement}

In the 1970s, the salient pathological and clinical features of CS were outlined in sentinel publications $[9,10,13]$. An expert pathologist is important to recognize key findings attributable to sarcoidosis versus other similar disorders. Grossly, the heart in CS will show scars in unusual locations with normal coronary arteries, indicating that the lesions are not ischemiarelated healed myocardial infarcts $[9,10]$. The hallmark of sarcoidosis, granulomatous inflammation, may involve any part of the heart $[9,10,67]$. Non-Necrotizing Granulomas (NNG) composed of epithelioid histiocytes, with multinucleated giant cells containing Schaumann bodies or asteroid bodies, lymphocytic infiltration, and patchy fibrosis may be observed $[1,9,10,12,27,67]$ (Figure $1 \mathrm{~A}-\mathrm{E}$ ). The myocardium is most frequently involved in CS; pericardial and endocardial involvement usually reflect extensions of myocardial disease $[9,10,16,68]$. Areas of involvement in descending order of frequency are the left ventricular free wall, Interventricular Septum (IVS), papillary muscles, Right Ventricle (RV), and atria $[9,16]$.

\section{Prognosis of cardiac sarcoidosis}

Cardiac involvement may occur at any point during the course of sarcoidosis and may occur in the absence of pulmonary or systemic involvement [13,15,16]. In 1977, 

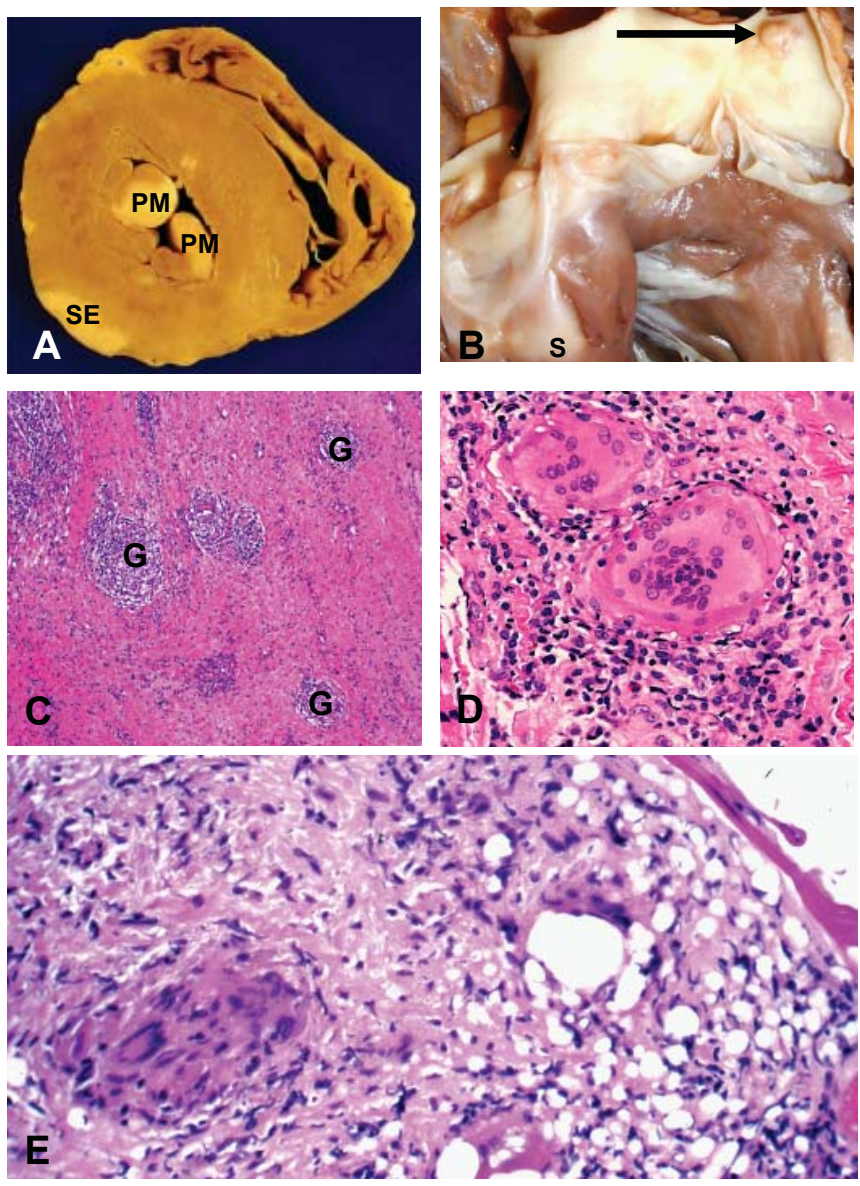

Figure 1: A \& B: Gross photographs of heart from young man dying suddenly while playing basketball.

A) cross-section of ventricles showing scars in papillary muscles (PM) and subepicardium (SE) with normal coronary artery characteristic of sarcoid lesions as opposed to ischemic injury.

B) Right ventricular outflow tract from same patient showing scarring below the pulmonary valve (S) and a granuloma in the pulmonary artery (arrow).

C) Histologic section of left ventricular lesion showing typical discrete, wellcircumscribed non-necrotizing granulomas (G) typical of sarcoidosis (H\&E stain, $x$ 40).

D) High magnification showing typical giant-cells with numerous nuclei (H\&E stain, x400).

E) Endomyocardial biopsy from patient resuscitated from sudden cardiac death, showing non-necrotizing granuloma typical of sarcoidosis (H\&E stain, x200). (Reproduced with permission from Semin Respir Crit Care Med, 2017, Sayah, et al. \{Sayah, 2017, Vol. 38, Pages 477-498\}.

Roberts, et al. described 35 necropsies of patients with CS at the National Heart Lung, and Blood Institute (NHLBI) and Armed Forces Institute of Pathology (AFIP) in the USA and reviewed 78 previously published necropsies with CS [9]. Interestingly, 24 of 113 patients (21\%) had no cardiac signs or symptoms. Among the entire cohort of 113 patients, 108 had sarcoid granulomas in the heart; five had myocardial scarring without granulomas. Macroscopic, grossly evident granulomas were present in the heart in 25 of 26 patients with clinically significant CS in the NHLBI subset. Among the 89 patients with clinically evident cardiac dysfunction, two-thirds died suddenly, presumably due to Ventricular Arrhythmias (VA) or Heart Block (HB); 23 percent died from progressive heart failure. All eight patients with left ventricular failure had extensive infiltration of the Left Ventricle (LV) at necropsy. Papillary muscle dysfunction was present in 16 patients; ventricular aneurysms were identified in eight patients. Recurrent pericardial effusions were fatal in three patients [9]. In 1978, Silverman, et al. reviewed 84 consecutive necropsies from patients with sarcoidosis seen at Johns Hopkins Hospital (USA) from 1899-1977; 23 patients (27\%) had granulomatous cardiac involvement [10]. Among four patients with widespread cardiac lesions, three had arrhythmias and sudden unexpected death. Of the 19 patients with microscopic myocardial granulomas, only four had symptoms attributed to CS [10]. In 1981, Fleming and Bailey reported a cohort of 197 patients with CS in the United Kingdom (UK); sudden death occurred in 48 (24\%) and was the presenting symptom in 34 (17\%) [17]. In 2001, Yazaki, et al. reported 95 Japanese patients with CS seen between 1984 and 1996; 40 died from cardiac causes during follow-up [Heart Failure (HF) in 29; sudden death in 11] [18]. Overall survival rates were $85 \%$ at 1 year, $60 \%$ at 5 years, and $44 \%$ at 10 years. Three parameters were independent predictors of mortality by multivariate analysis: 1) New York Heart Association functional class [Hazard Ratio (HR) 7.7 per class increase, $p=0.0008$ )]; 2) left ventricular end-diastolic diameter [HR 2.6 per $10 \mathrm{~mm}$ increase, $\mathrm{p}=0.02$ ]; 3) Sustained Ventricular Tachycardia (SVT) [HR 7.2, $\mathrm{p}=0.03)][18]$.

While CS is often clinically silent for months or even years, attributable mortality rates of up to $50-85 \%$ in necropsy series of CS have been cited $[13,14,63,69]$. In one necropsy series in the USA, 10 of 25 deaths attributed to CS had no extra-cardiac disease [16]. Hu, et al. reviewed necropsies from 44 cases with sarcoidosis seen at the Mayo Clinic over 20 years (1994-2013) [14]. Sarcoidosis was not diagnosed antemortem in 16 (36\%). Overall, 15 deaths were due to sarcoidosis (7 due to CS) [14]. Most deaths due to CS are due to VA or conduction defects; HF due to massive granulomatous infiltration of the myocardium accounts for at least $25 \%$ of deaths $[1,9,10,13,18]$. Radionuclide imaging studies to identify active sites of granulomatous inflammation are critical as early treatment may avert the potentially lethal progression of the cardiac lesion(s).

\section{Conduction disturbances and arrhythmias}

Conduction disturbances and arrhythmias are the most common cardiac manifestations of sarcoidosis and reflect granulomatous infiltration within the conduction system [e.g., Sinoatrial (SA) node, Atrioventricular (AV) node, Bundle of His] or ventricular walls [1,9]. AV Block (AVB) [70] is the most common arrhythmic manifestation of CS (26-67\%) [71], but Bundle Branch Block (BBB), nonspecific interventricular conduction delay, Premature Ventricular Contractions (PVCs), Ventricular Tachycardia (VT), and other arrhythmias may occur $[9,72,73]$. A prospective study in Ottowa, Canada evaluated 32 adults $<60$ years old (2010-2013) with unexplained $2^{\text {nd }}$ or $3^{\text {rd }}$ degree AVB and no previous history of sarcoidosis in any organ [74]. ${ }^{18}$ Fluorodeoxyglucose $\left({ }^{18} \mathrm{FDG}\right)$ Positron Emission Tomography (PET) scans were consistent with CS in 11 (34\%); extra-cardiac sarcoidosis was subsequently confirmed in all 11 cases. During an average follow-up of $21+/-9$ months, Adverse Cardiac Events (ACE) were documented in three: HF $(n=3)$; VT $(n=2)$ [74]. In the series reported by Roberts, et al. in the USA, Electrocardiograms (ECGs) demonstrated PVCs (29\%), 
Complete Heart Block (CHB) (22\%), complete BBB (22\%), VT $(17 \%)$, and atrial arrhythmias (16\%) [9]. In an English series of 300 patients with CS, predominant features included: VA (45\%); BBB (38\%); supraventricular arrhythmias (28\%); sudden death $(16 \%)$ [75]. Atrial arrhythmias may reflect atrial dilatation secondary to ventricular dysfunction, pulmonary parenchymal involvement, or direct atrial involvement from granulomas or scar tissue [69]. In a retrospective study of 100 patients with CS in the USA, 32\% had supraventricular arrhythmias [atrial fibrillation (AF) (18\%); atrial tachycardia (7\%); atrial flutter ( $5 \%)$, supraventricular tachycardia (2\%)] during a mean follow-up of 5.8-years [76]. Left Atrial Enlargement (LAE) was more frequent in those with atrial arrhythmias and increased the likelihood of supraventricular arrhythmias on multivariate analysis (RR 6.12) [76]. In any sarcoid patient with arrhythmias, early involvement of electrophysiologists as part of a multidisciplinary team is essential [77].

\section{Cardiomyopathy}

Dilated cardiomyopathy and HF may result from extensive myocardial sarcoidosis $[18,45]$. In a study of 43 patients with CS seen at Johns Hopkins Hospital, cardiomyopathy was present in $21(49 \%)$ and was associated with a mortality of $62 \%$ [45]. Other features included syncope in 14 (33\%); HB in $13(30 \%)$; tachyarrhythmias in 12 (28\%). In a Japanese study of CS, HF was the most common cause of death [56]. In a subsequent study, these investigators described 95 Japanese patients with CS [18]. The diagnosis was made at necropsy in 20 cases; CS was diagnosed antemortem in 75 cases; all 75 were treated with steroids. During a mean follow-up of 68 months, 29 of 75 (39\%) died of HF and 11 (15\%) died suddenly [18].

\section{Ventricular aneurysms}

Ventricular aneurysms rarely complicate CS. Most publications have been isolated case reports in CS patients presenting with HF or VA [78-81]. However, in a retrospective study of 50 cases of CS seen at a tertiary cardiovascular center in Japan from 1986-2012, 20 (40\%) had ventricular aneurysms [82]. During a mean follow-up of $59+/-69$ months, composite cardiac events were more common in the aneurysm group ( $\mathrm{p}$ $=0.04$ ) and cardiac deaths (including sudden death and HF deaths) were more common in the aneurysm group $(p=0.03)$ Kaplan-Meier survival curves showed composite event-free survival was significantly lower in the aneurysm group. Tenyear survival rates were $66.9 \%$ in the aneurysm group compared to $96.7 \%$ in the non-aneurysm group [82]. In a cohort of 113 necropsy cases with at the NHLBI (USA), ventricular aneurysms were present in eight; 7 of 8 with ventricular aneurysms had been treated with steroids, suggesting that steroids may promote aneurysm formation [9].

\section{Involvement of cardiac valves}

Severe involvement of cardiac valves is rare $(<3 \%)[9,10,19]$, but valvular dysfunction may result from sarcoid involvement of the papillary muscles [9,83]. Severe granulomatous infiltration mandating mitral valve replacement has been described $[19,84]$. Less commonly, the tricuspid, aortic, or pulmonary valves are involved [9].

\section{Pericardial involvement}

Infiltration of the pericardium may lead to pericardial effusion(s) [9,85-88] and, rarely, constrictive pericarditis [89]. In most patients with pericardial involvement myocardial involvement is also present [9]. In one study, 13 of 14 sarcoidosis patients with pericardial effusions had abnormal ${ }^{99}$ technetium ( $\left.{ }^{99} \mathrm{Tc}\right)$-pyrophosphate scans, consistent with infiltrative cardiomyopathy [88].

\section{Cardiac vasculature}

Coronary arteries are typically normal in patients with CS. Myocardial scars in the absence of coronary disease is typical of CS $[9,10]$. Coronary arterial aneurysms [90], coronary artery spasm [91], acute coronary syndrome, [92] and coronary artery vasculitis [93] have been described in CS, but are exceptionally rare.

\section{Involvement of other organs}

Extra-cardiac involvement is usually present in patients with CS [4], but symptoms may be absent until the initial presentation with Sudden Cardiac Death (SCD) $[9,16]$. In the necropsy series of 35 cases of CS from the NHLBI (USA), 26 patients died of arrhythmias or conduction disturbances [9]. In this subset, 25 (96\%) had lymph node involvement; 20 (77\%) had lung involvement; 17 (68\%) had hepatic granulomas. In a British study of 20 necropsies in patients with CS, other sites of organ involvement included: lungs in 19 (95\%); lymph nodes 19 (95\%); spleen, 7 (35\%); liver, 7 (35\%) [61]. Among 95 Japanese patients with CS, extra-cardiac involvement included: lungs in 56 patients (59\%); eye in $39(41 \%)$; skin in $16(16 \%)$ [18]. In a French study of 41 patients with CS, extra-cardiac involvement was present in all cases [27]. In $63 \%$ of cases, cardiac involvement developed during follow-up of extra-cardiac sarcoidosis [27]. In a series of 73 cases of CS seen at the University of Cincinnati (USA) over 6 years, all had extra-cardiac involvement [most commonly lung (94.5\%)] [4]. A study from Western Australia reported 52 cases of CS; $91 \%$ had lung involvement; the mean number of extra-cardiac sites was 2.2 [94]. Given the high incidence of extra-cardiac involvement in patients with CS, biopsies of lung, mediastinal or hilar lymph nodes, liver, or skin are indicated when clinical features, radiographic techniques (HRCT scan or PET), or magnetic resonance imaging indicate probable involvement at those sites [95-97]. Examination by an expert ophthalmologist is reasonable to determine if ocular involvement (principally uveitis) is present [97]. However, blind biopsies in the absence of specific radiographic or clinical findings are not appropriate due to low yield.

\section{Isolated cardiac sarcoidosis}

Isolated CS is uncommon, but some studies cited a lack of extra-cardiac involvement $[16,98]$. In a necropsy study in the USA, 12 of $25(40 \%)$ patients who died as a result of CS had no signs of extra-cardiac involvement [16]. In a retrospective study from Finland, 33 of 52 (66\%) patients with CS seen between 2000-2010 had disease isolated to the heart [98]. In a more recent study from Finland, 351 cases of CS were reported 
from 1998-2015, although an antemortem diagnosis was made in only 262 cases [99]. High-grade AVB was the most common first sign of CS ( $42 \%)$, followed by HF (17\%), unexpected SCD or aborted SCD (14\%), and sustained VT (14\%). Of all deaths until the end of $2015,54 / 84$ (64\%) were unexpected SCD due to CS that was clinically silent during life or defied all attempts at diagnosis [99]. Kaplan Meier's estimate of survival was $85 \%$ at 5 -years and $76 \%$ at 10 years [99].

\section{Diagnosis of cardiac sarcoidosis}

The definitive diagnosis of isolated CS is difficult. The yield of Endomyocardial Biopsies (EMB) is low and clinicians often rely on non-invasive imaging to diagnose and follow CS. Treatment of CS is often warranted even in the absence of histologic proof. Guidelines to diagnose CS were developed in 1993 by the Japanese Ministry of Health and Welfare [100] and in 1999 by the research group in the USA conducting the ACCESS study [101]. In 2014, an international consensus statement regarding diagnosis and management of CS was written by experts chosen by the Heart Rhythm Society in collaboration with representatives from the American College of Cardiology (ACC), American Heart Association (AHA), American College of Chest Physicians (ACCP), the World Association of Sarcoidosis and Other Granulomatous Disorders (WASOG), and other societies [102]. Given the potential mortality associated with CS, early diagnosis and treatment is critical and may be lifesaving. Serum Angiotensin Converting Enzyme (SACE) levels are insensitive for CS [103]. The presence of abnormal ECG or $\mathrm{HF}$ is a nonspecific feature. Techniques to diagnose CS have evolved over the past 3 decades. Gadolinium (Gd)-enhanced cardiac magnetic resonance imaging (Gd-CMR) [104] and ${ }^{18} \mathrm{FDG}-\mathrm{PET}[105,106]$ are the best tests to determine the presence and extent of cardiac involvement (discussed in detail later).

\section{Electrocardiogram}

A resting ECG is recommended by WASOG and the American Thoracic Society (ATS) as an appropriate screening test in all patients with sarcoidosis [107]. Abnormalities on ECG (e.g., conduction disturbances, arrhythmias, or nonspecific ST and T-wave changes) have been noted in 20 to $31 \%$ of sarcoid patients $[7,10,108-110]$. In one necropsy study, $42 \%$ of sarcoid patients with mild cardiac involvement (microscopically evident granulomas) and $75 \%$ of patients with severe involvement (gross evidence of cardiac granulomas or infiltration at necropsy) had arrhythmias or conduction disturbances [10]. However, a large cohort of Caucasian Scandinavians (Swedes) $(n=1,017)$ was retrospectively screened for CS at disease onset with ECG and the presence or absence of cardiac-related symptoms [110]. Abnormalities on ECG were present in 166 (16.3\%) and CS was diagnosed later in $22(13.2 \%)$ in this group. In sharp contrast, CS developed in only one of $801(0.1 \%)$ patients with a normal ECG. The risk for CS was higher in patients with an abnormal ECG combined with cardiac symptoms [11/40 (27.5\%)] compared to abnormal ECG without cardiac symptoms [11/126 (8.7\%), p $<0.01]$. Further, patients with Lofgren's syndrome (LS) had a reduced risk of CS compared to those without LS $(\mathrm{p}<0.05)$ [110].
This suggests an extraordinarily low risk of CS in the presence of a normal ECG in this homogeneous population, but may not necessarily apply to other ethnicities (e.g., Blacks or Japanese). Nonetheless, resting ECGs are insensitive for detecting cardiac involvement. Further, the clinical significance of nonspecific ECG abnormalities is unclear. Polish investigators assessed risk for CS in a cohort of 201 Caucasians with sarcoidosis seen between 2012-2015 [111]. CMR was consistent with CS in 49 $(24.4 \%)$. The univariate analysis cited the following factors associated with increased risk of CS ( $\mathrm{p}<0.01$ in all): male sex (OR 2.5); cardiac-related symptoms (OR 3.53); extra-thoracic sarcoidosis (OR 3.48); elevated serum pro- $\mathrm{N}$-terminus brain natriuretic protein (pro-NT-BNP) (OR 3.82); any abnormality on ECG (OR 5.38); contemporary radiographic progression of sarcoidosis in lungs (OR 2.98). Abnormalities on transthoracic echocardiogram (TTE) and Holter ECG were also risk factors, but not significant in multivariate analysis [111]. Elevated proNT-BNP coupled with abnormal ECG was associated with the specificity of $93 \%$, a higher specificity than Holter or exercise tests [111], and may be a cost effective way to assess the risk of CS in patients with an abnormal ECG.

\section{Transthoracic Echocardiography (TTE)}

Transthoracic echocardiography is nonspecific but is invaluable to assess cardiac chamber(s) size and function in patients with suspected or confirmed CS $[7,68]$. In early studies, abnormalities on TTE were detected in $14 \%$ to $41 \%$ of patients with sarcoidosis, even in the absence of ECG abnormalities and clinical symptoms $[6,7]$. Salient abnormalities include global or focal hypokinesis or dyskinesia; wall motion abnormalities; chamber enlargement; ventricular wall thinning or aneurysms; ventricular dilatation or hypertrophy; depressed Ejection Fraction (EF); diastolic dysfunction; valvular regurgitation; papillary muscle dysfunction; pericardial effusions [1,112]. In some cases, macroscopic areas of bright echoes were noted, reflecting granulomatous inflammation [113], described as a "speckled or snowstorm pattern" [62]. Wall thinning or thickening of the IVS localized to the basal portion is characteristic of CS $[68,113,114]$. Yazaki, et al. reported TTE findings from 15 patients with CS and 30 patients with idiopathic dilated cardiomyopathy (IDC) [68]. Thinning $(<7$ $\mathrm{mm}$ ) or thickening ( $>13 \mathrm{~mm}$ ) of the ventricular wall (typically in the IVS) were noted in 11 of $15(73 \%)$ patients with CS. ECG demonstrated HB in all 11 patients. By contrast, only $17 \%$ of patients with IDC had abnormal wall thickness. Interestingly, ${ }^{201}$ thallium scans, performed in 14 patients with CS in that study, revealed perfusion defects in 13 (93\%) [68]. Echocardiography alone is not sensitive to detect early myocardial sarcoid lesions $[3,7]$ but is noninvasive and a relatively inexpensive way to assess and follow cardiac size and function.

Two-Dimensional Speckle-Tracking

(2D-ST) echocardiography is more sensitive than conventional TTE for detecting early CS in patients with normal or mild cardiac dysfunction [115-118]. However, since 2D-ST is rarely performed in most medical centers, we will not further discuss this technique. 


\section{Radionuclide scans}

Radionuclide scans are integral to the diagnosis of CS. Beginning in the 1970 s and 1980s, gallium67 $\left(\mathrm{Ga}^{67}\right)$-citrate $[103,119]$ and thallium ${ }^{201}\left(\mathrm{Tl}^{201}\right)$ scans $[6,103,119,120]$ were used to diagnose and follow CS. In sentinel studies, $\mathrm{T}^{201}$ scans were superior to TTE to diagnose CS $[6,103,120,121]$. Tellier, et al. described a phenomenon of "reverse distribution" in CS [120]. Perfusion defects were present on $\mathrm{Tl}^{201}$ scans at rest in 16 patients with CS; the perfusion defects improved or completely resolved in 13 of 16 patients with exercise or dipyridamole [120]. Other studies affirmed that perfusion defects noted at rest in CS disappeared or decreased in size following exercise or infusions of dipyridamole or adenosine $[6,122]$. This differs from coronary artery disease, in which defects at rest worsen or fail to improve with exercise, dipyridamole, or adenosine
$[6,123]$. The above studies are useful primarily for historical interest as these radionuclide techniques have been supplanted by ${ }^{18} \mathrm{FDG}-\mathrm{PET}[104,124]$ and Gd-enhanced CMR [124,125] to diagnose and/or monitor CS.

\section{Positron emission tomography (PET)}

${ }^{18}$ FDG-PET has been used to diagnose and "stage" sarcoidosis in thoracic and extra-thoracic sites [126-128], including CS $[94,124,127,129,130]$ (Figures 2-6). Increased update of ${ }^{18} \mathrm{FDG}$ occurs within activated leukocytes, macrophages, and $\mathrm{CD}_{4}+$ $\mathrm{T}$ lymphocytes, major components of granulomas [128], and correlates with inflammation in the lung or extra-pulmonary sites [126,127]. ${ }^{18}$ FDG-PET is a sensitive marker of disease activity in sarcoidosis $[129,131]$ and is superior to $\mathrm{Ga}^{67}$-citrate [132] and $\mathrm{Tl}^{201}$-scans [133] to diagnose CS. The specificity of PET

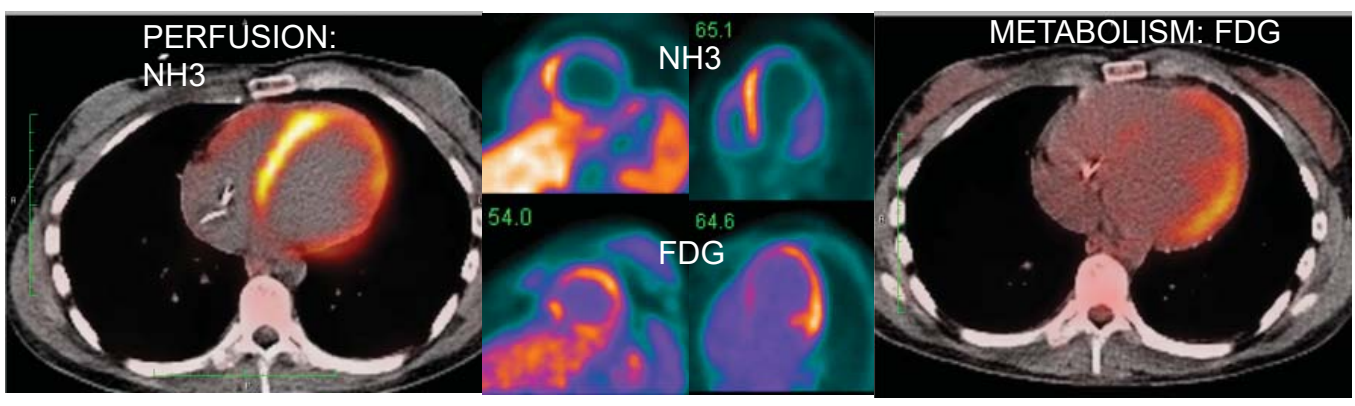

Figure 2: Patient with nonischemic cardiomyopathy and VT with mismatch. Perfusion shows normal septal update with decreased lateral uptake by NH3. On FDG, the myocardial uptake is increased on the lateral wall, which indicates inflammation. Reproduced with permission from Semin Respir Crit Care Med, 2017, Sayah, et al. \{Sayah, 2017, Vol. 38, Pages 477-498\}.

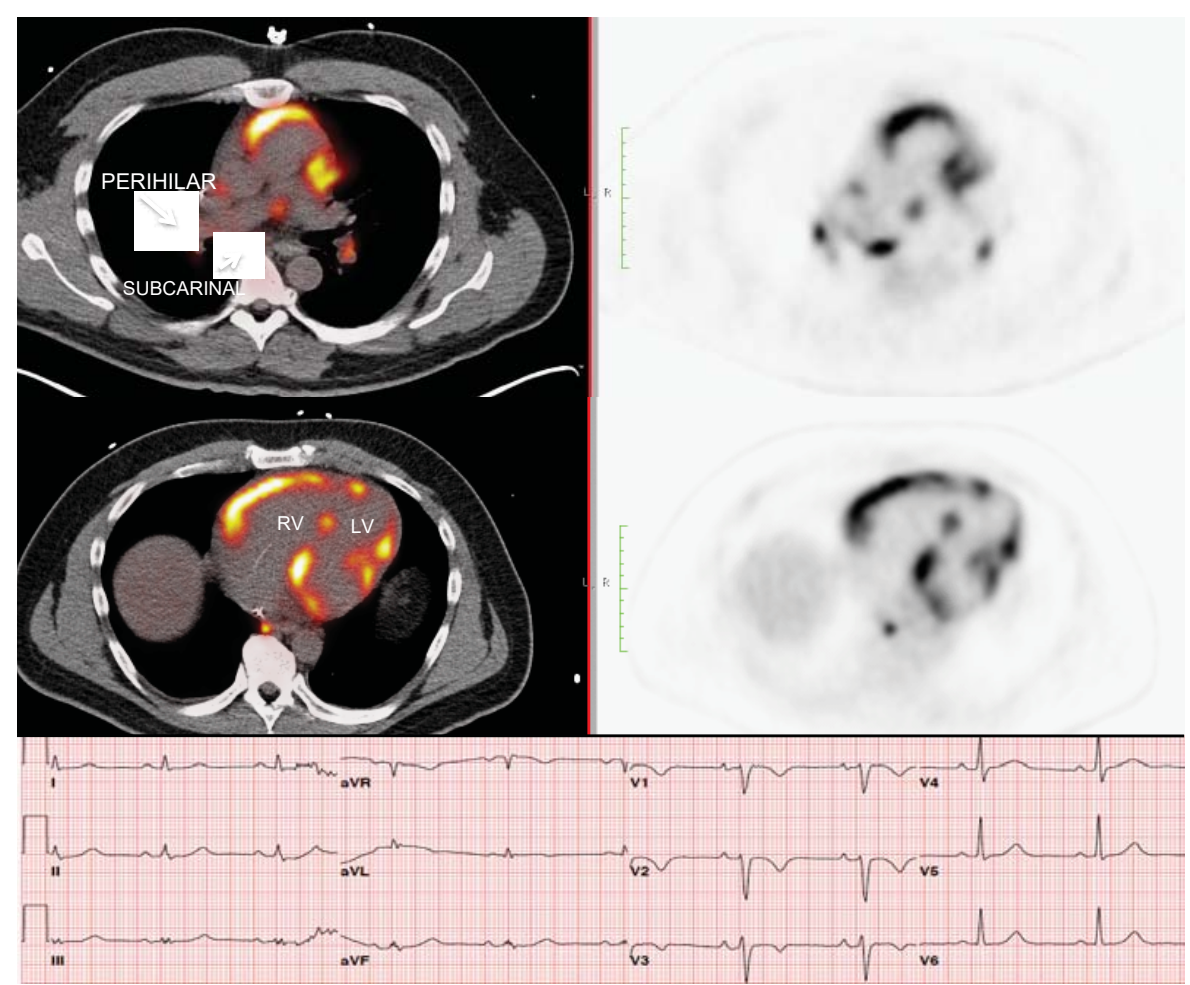

Figure 3: Patient referred for VT ablation with presumed ARVD with right precordial T wave inversion. PET scan demonstrated ${ }^{18}$ FDG uptake in right hilar lymph node and patchy focal uptake throughout both ventricles. Biopsy of the hilar node revealed non-necrotizing granulomas (NNG) consistent with sarcoidosis. Reproduced with permission from Semin Respir Crit Care Med, 2017, Sayah, et al. \{Sayah, 2017, Vol. 38, Pages 477-498\}. 
as a diagnostic tool in CS relies on the suppression of normal myocyte uptake of glucose. For this reason, prolonged fasting ( $>12$ hours) and fatty acid loading [134,135] are required before imaging to suppress myocardial glucose metabolism in favor of oxidation of free fatty acids [136]. PET scans in CS may show different patterns of diffuse and focal uptake (Figure 2) [137]. Three basic patterns in CS have been observed: diffuse, focal, and focal on diffuse; perfusion abnormalities may also be present [102] (Figures 4-6). In an early study in Japan, 17 cases of CS had ${ }^{18}$ FDG-PET, Tl ${ }^{201}$, and $\mathrm{Ga}^{67}$ scans [133]. ${ }^{18} \mathrm{FDG}$-uptake in the heart was increased in $14 / 17$ (82\%) whereas abnormal myocardial uptake was noted in only six (35\%) and three (18\%) cases on $\mathrm{Tl}^{201}$ or $\mathrm{Ga}^{67}$ scans, respectively. ${ }^{18} \mathrm{FDG}-\mathrm{PET}$ scans were repeated in seven patients after one month of steroid therapy; ${ }^{18} \mathrm{FDG}$ defects disappeared entirely in five and improved in two [133]. In 2012, a meta-analysis of all studies relevant to ${ }^{18}$ FDG-PET to diagnose CS reported pooled sensitivities and specificities of $89 \%$ and $78 \%$, respectively [105].

Focal perfusion defects and ${ }^{18} \mathrm{FDG}$ uptake on PET in patients with suspected CS assess the presence or absence of inflammation [35,36,134]. Early in the course of CS, PET may show focal ${ }^{18} \mathrm{FDG}$ uptake at sites of granulomatous inflammation without associated perfusion defects [35]. In later stages, after the inflammation has "burned out", perfusion defects may persist whereas ${ }^{18} \mathrm{FDG}$ uptake resolves [35]. Serial PET scans have been used to evaluate response to therapy in CS and prognosis [36-38,133,138] but randomized trials are lacking. Reduction in ${ }^{18} \mathrm{FDG}$ uptake has been noted following therapy with steroids and has been associated with improved prognosis $[37,133,139]$. Serial PET scans were performed in 16 patients with CS before and during treatment [36]. Quantitative assessment of ${ }^{18} \mathrm{FDG}$-avid cardiac lesions was interpreted via four PET parameters; the clinical response was evaluated by symptoms and clinical criteria. Quantitative PET parameters significantly declined (inflammation improved) on repeat PET in patients who clinically were stable or improved whereas those whose PET had not improved were clinically worse [36]. Shelke, et al. evaluated 15 patients with CS who had PET scans before and after initiation of steroid therapy (126+/- 54 days post) [37]. Four cases were considered nonresponders [defined as lack of improvement or worsening in clinical outcomes (i.e., VA, HF, LV systolic function) despite steroid therapy]. Myocardial maximum standardized uptake of ${ }^{18} \mathrm{FDG}$ (SUV max) declined (improved) significantly in 11 patients responding to steroids $(\mathrm{p}=0.004)$ but increased in non-responders $(\mathrm{p}<0.05)$ on follow-up. Further, the number of LV segments with ${ }^{18} \mathrm{FDG}$ uptake declined significantly in responders $(p=0.007)$ but trended towards increase in nonresponders $(p=0.465)$. Importantly, heterogeneous uptake on baseline PET and increase in intensity and area of myocardial involvement on follow-up were associated with poor clinical outcomes despite steroid therapy [37]. In another study of 118 cases with known or suspected CS, ${ }^{18} \mathrm{FDG}$-PET scans were abnormal in $71(60 \%)$ [134]. Over a median follow-up of 1.5 years, Adverse Cardiac Events (ACE) occurred in 31 (26\%) and included 27 episodes of VT and 8 deaths. Cardiac PET findings were predictive of ACE; the presence of both a perfusion defect and abnormal ${ }^{18} \mathrm{FDG}$ update (29\% of patients) was associated with an HR of $3.9(\mathrm{p}<0.01)$ for ACE and remained significant after adjusting for LVEF and clinical criteria [134]. Serial ${ }^{18} \mathrm{FDG}-$ PET scans were done in 34 pts with CS (mean of 4 per patient during 2.3 years of follow-up) at Stanford (USA) from 20102017 [38]. Presenting symptoms included advanced HB [ $\mathrm{n}=12$ (35\%], HF [n $=12(35 \%)]$, and VA [n = $14(41 \%)]$. At baseline, PET showed increased cardiac ${ }^{18} \mathrm{FDG}$ uptake in $27 / 34$ (79\%),

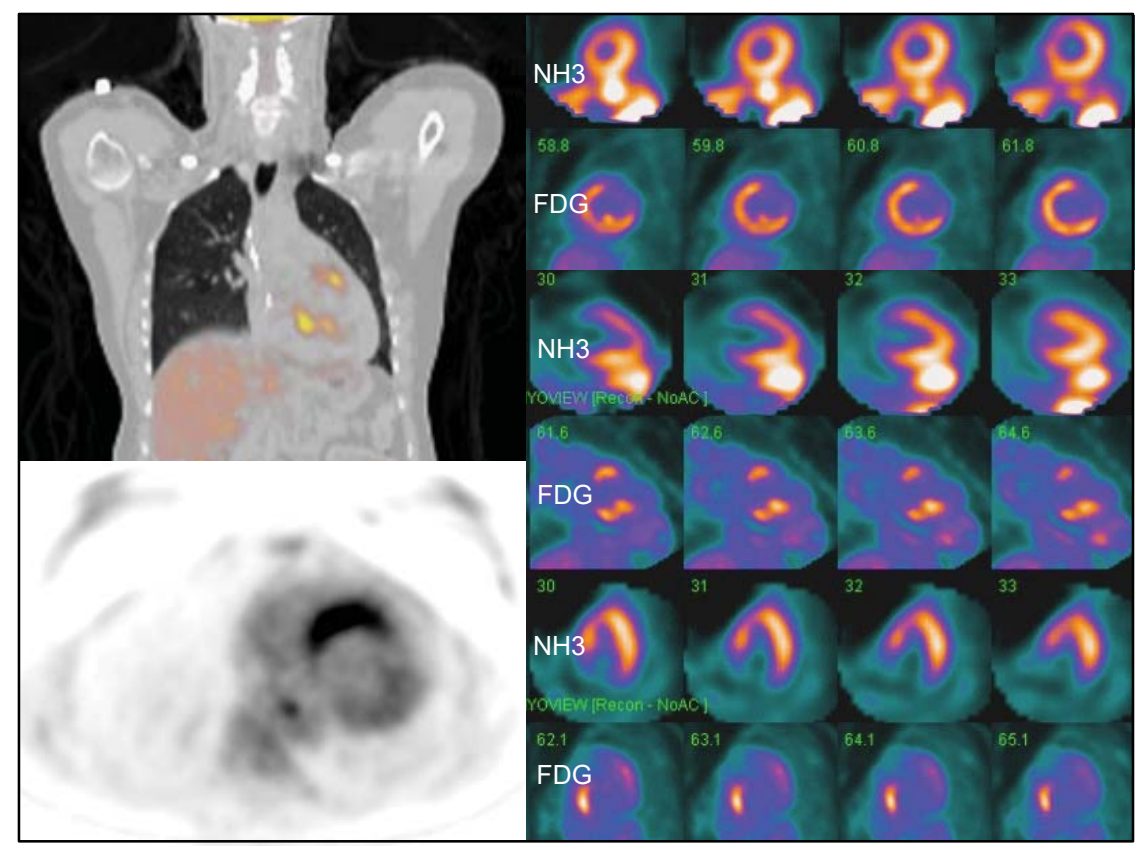

Figure 4: Multiphase inflammation in a 49-year old female with a history of heart block requiring a pacemaker. She was found to have nonsustained VT on pacer interrogation. PET scan revealed decreased anteroseptal perfusion with focal uptake of ${ }^{18} \mathrm{FDG}$ in the septum and inferolateral wall. The mismatch in the septum suggests chronic scarring; increased uptake in the inferiorlateral region suggests active inflammation. Reproduced with permission from Semin Respir Crit Care Med, 2017, Sayah, et al. \{Sayah, 2017, Vol. 38, Pages 477-498\}. 


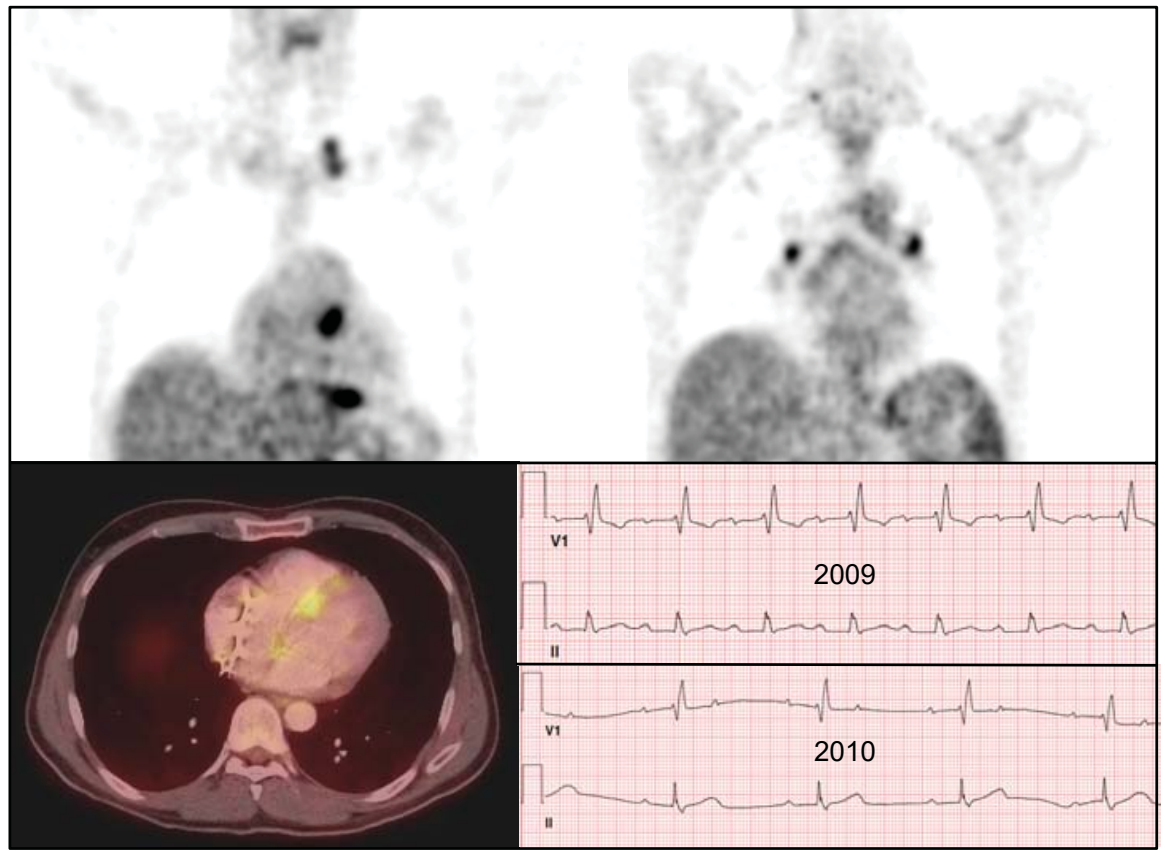

Figure 5: Typical bilateral hilar uptake and patchy myocardial uptake in the septum with progressive heart block in a patient presenting with intermittent lightheadedness. Reproduced with permission from Semin Respir Crit Care Med, 2017, Sayah et al \{Sayah, 2017, Vol. 38, Pages 477-498\}.

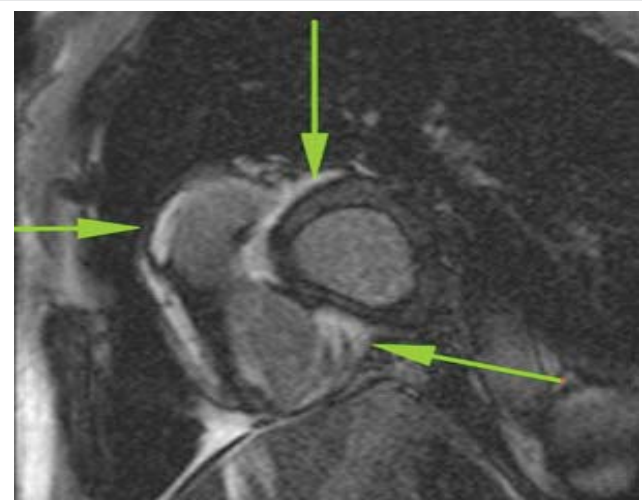

Figure 6: MRI delayed enhancement throughout RV in a 48-year old male with recurrent VT of RV origin and suspected ARVD. An ICD was placed and he was treated medically for VT. MRI showed diffuse hyperenhancement of the RV, extending in the left ventricular septum. The RV was dilated and hypokinetic. PET/ CT was consistent with sarcoidosis. Lymph node biopsy revealed NNG consistent with sarcoidosis. With treatment of his sarcoidosis, VT has not recurred. Reproduced with permission from Semin Respir Crit Care Med, 2017, Sayah et al \{Sayah, 2017, Vol. 38, Pages 477-498\} [1].

consistent with active CS; seven (21\%) showed no active CS. The most common pattern was patchy uptake $(n=21)$; four showed patchy on diffuse ${ }^{18} \mathrm{FDG}$ uptake. At a median follow-up of 2.3 years, 25 patients $(74 \%)$ had received prednisone (pred) and 26 $(76 \%)$ had been treated with pred + methotrexate (MTX). Nine $(26 \%)$ received tumor necrosis factor-a $(\mathrm{TNF}-\alpha)$-antagonists after failing pred + MTX. At follow-up, $48 \%$ of patients had been weaned from pred completely and $20 \%$ were on a low maintenance dose (5 to $10 \mathrm{mg})$. Overall, two patients (6\%) had died (one due to infection) [38].

While ${ }^{18} \mathrm{FDG}-\mathrm{PET}$ is a pivotal test in patients with CS for initial diagnosis and follow-up, pitfalls have been noted including 1) physiological uptake of ${ }^{18} \mathrm{FDG}$ in myocardium may be found in healthy subjects; 2) normal myocardium may exhibit increased physiologic uptake on the basal and lateral LV walls; 3) apparent increased uptake of ${ }^{18} \mathrm{FDG}$ in myocardium may reflect diet (i.e. not adhering to a low carbohydrate/high-fat diet for at least 12 hours prior to the test); 4) pulmonary hypertension increases RV and IVS ${ }^{18} \mathrm{FDG}$ update because of the mechanical overload; 5) nonspecific ${ }^{18} \mathrm{FDG}$ uptake may be observed in patients with non-sarcoid dilated cardiomyopathies; 6) interpretation may not be straightforward [3]. Artifactual inhomogeneities in PET may be seen in normal myocardium due to the influence of in-plane resolution and wall thickness [140]. Although ${ }^{18} \mathrm{FDG}-$ PET has assumed an important role to diagnose and follow CA sarcoidosis, many centers combine ${ }^{18} \mathrm{FDG}-\mathrm{PET}$ with Gd-CMR to diagnose and follow CS $[38,40,42,104,125,141,142]$, as these dual procedures may provide complementary information. ${ }^{18} \mathrm{FDG}$ is more sensitive for early phases of inflammation, but Gd-CMR is more specific for later phases of scar formation $[143,144]$. Unfortunately, PET-CT and CMR are incredibly expensive (often $>\$ 10,000$ per study in the USA) and may not be covered by insurance.

\section{Cardiac MRI (CMR)}

CMR may identify regional differences in enhancement between diseased and normal myocardial tissue [145,146]. Gadolinium contrast media distributes rapidly into the extracellular space of the myocardium and is excluded from normal myocardial cells. Late gadolinium enhancement (LGE) is typical of CS $[143,146,147]$. In the setting of fibrosis, regional enhancement of myocardial scar tissue is present [143]. In CS, CMR may demonstrate diffuse or focal enhancement, particularly in the myocardial wall or subepicardial region, thought to reflect edema associated with inflammation in 
addition to myocardial scar [145,146,148] (Figure 6). Early experience with CS showed that CMR was superior to TTE [149-151]. In a sentinel study, 16 patients with suspected CS had CMR; localized enhancement of signal intensity on T1weighted images was present in the LV in eight patients (50\%) indicating interstitial edema or scarring [150]. Two patients with LGE also had thinning of the LV septal wall. After one month of steroid therapy, the high-intensity signals had markedly diminished in all patients. Importantly, TTE were abnormal in only two patients [150]. In another prospective study, both $\mathrm{Tl}^{201}$ scans and CMR were done in 40 patients with sarcoidosis; CMR were abnormal in all five with CS and 17 of 31 (54\%) with multi-organ sarcoidosis but without cardiac symptoms [152]. Findings included increased intra-myocardial signal intensity $(\mathrm{n}=5)$, focal or patchy increased signal intensity, with or without myocardial thickening $(n=10)$, focal increased signal only on T2-weighted images $(n=2)$ [152]. In 2005, Smedema, et al. reported 58 patients with biopsy-proven pulmonary sarcoidosis who had both $\mathrm{Tl}^{201}$ scans and CMR; 12 (21\%) had CS [147]. CMR revealed myocardial LGE in 19 patients, mostly involving basal and lateral segments. In eight of the 19 patients, $\mathrm{Tl}^{201}$ scintigraphy was normal. The sensitivity and specificity of CMR were $100 \%$ (CI, 78-100\%) and 78\% (CI, 64$89 \%$ ), respectively [147]. In 2008, Ichinose, et al. reported 40 patients with sarcoidosis; 11 had CS [153]. Myocardial hyperenhancement was noted in 10 of 11 patients with CS but in none of 29 patients without CS. Myocardial hyper-enhancement was most frequent in the subepicardial and mid-myocardial layers ( $\mathrm{p}<0.001)$ [153]. In two studies comprising five patients with CS, LGE was present on CMR, mainly distributed in the mid-to epi-myocardium $[154,155]$. In another study, 17 patients with CS had both EMB and CMR; CMR was consistent with CS in 13 of $17(76 \%)$ patients whereas EMB were positive in only six (35\%) [156]. Sensitivities and specificities with CMR were $76 \%$ and $92 \%$, respectively, compared to $35 \%$ and $100 \%$, respectively, with EMB [156]. Multi-contrast LGE on CMR may exhibit improved sensitivity for CS [124]. Additionally, LGE may be a marker of myocardial damage in patients with normal cardiac function [157]. Investigators at the University of Chicago reported a cohort of 152 cases of biopsy-confirmed extracardiac sarcoidosis who had normal LVEF (>50\%) and were followed for 651 days (2007-2010) [157]. Foci of myocardial LGE were present in $29(19 \%)$ and were associated with a greater prevalence of abnormal ECG ( $76 \%$ vs $31 \%$, p < 0.001$)$, diastolic dysfunction $(67 \%$ vs $33 \%, \mathrm{p}=0.05)$, reduced RVEF ( $49 \%$ vs $55 \%, \mathrm{p}=0.012$ ), and NSVT ( $33 \%$ vs $6 \%$ ) compared to cases with no myocardial LGE [157]. Thus, even small foci of myocardial LGE may identify patients with a myocardial injury who may be at risk for NSVT and ACE. Cheong, et al. performed CMR in 31 patients with confirmed extra-cardiac sarcoidosis but no history of heart disease or cardiac symptoms [158]. Abnormal myocardial CMR (LGE) was evident in 8/31 (29\%) that suggested small foci of myocardial injury or fibrosis may put patients at risk for late ACE [158].

Cardiac lesions may appear as patchy or focal hyperenhancement patterns in the LV free wall, papillary muscles, or IVS $[124,139,148]$. Numerous studies have shown that CMR achieved sensitivities of 75 to $>95 \%$ in CS with specificities of $~ 75-80 \% \quad[145,147,158,159]$. LGE on CMR (possibly reflecting the absence of viable myocytes in a collagenous scar) may serve as a prognostic indicator for the severity of disease [41,42,154,155,160]. Among 61 consecutive patients with CS seen in the Netherlands from 2002 to 2012, 37 had CMR; LGE was present in 26 cases [41]. Compared to patients without LGE, there was a trend to a higher rate of VA ( $29 \%$ vs $0 \%, p=0.12$ ) and higher rate of composite clinical endpoint (i.e., VA, HF hospitalization, or cardiovascular death) in those with LGE ( $41 \%$ vs $0 \%, \mathrm{p}<0.05$ ) [41]. By contrast, in a prospective study in Japan, 61 cases of sarcoidosis without clinical cardiac manifestations had CMR; LGE was present on CMR in eight (13\%) [161]. Thinning of the IVS on TTE was an independent predictor of myocardial LGE. Study end-point was a composite of all-cause deaths, symptomatic arrhythmias, or HF necessitating admission. During follow-up of $50+/-12$ months, there was no significant difference in ACE [161]. In a study of 19 Japanese cases with CS, the total number of affected myocardial segments on CMR correlated with duration of sarcoidosis in cases with onset in extra-cardiac sites $(\mathrm{p}=0.005)$ as well as LV ejection fraction (LVEF) and LV diastolic volume [155]. All patients with LVEF $<30 \%$ had both subepicardial and transmural lesions. In Finland, 59 patients with CS had CMR from 2004-2015; the prognostic significance of myocardial LGE and thickness of the basal IVS were analyzed [162]. By April 2015, 23 patients had reached the study endpoint, consisting of a composite of cardiac death $(n=3)$; cardiac transplant $(n=1)$; life-threatening cardiac events $(n=19)$. In univariate analysis, myocardial extent of LGE predicted event-free survival as did scar-like thinning $(<4 \mathrm{~mm})$ of the basal IVS and the RVEF $(\mathrm{p}<0.05$ for all). In multivariate Cox regression analysis, only the extent of myocardial LGE independently predicted outcome (HR $=2.22$ per tertile) [162]. In a later study, these investigators retrospectively reviewed 73 cases of Giant Cell Myocarditis (GCM) and determined that 45 cases had intraor extra-cardiac granulomas consistent with CS [163]. Patients relocated to CS had less $\mathrm{HF}$ at presentation $(20 \%$ vs $46 \%$, p < 0.017 ) and better one-year transplant-free survival compared to GCM ( $82 \%$ vs $45 \%, \mathrm{p}=0.011$ ) [163]. A recent meta-analysis reviewed 19 publications up until 2020 regarding the risk of ACE and SCD in patients with symptomatic CS [164]. Positive LGE-MRI and PET were associated with an 8.60 and 9.07 fold increased risk of VA, respectively, and a 6.82 and 3.41 fold increased risk of major ACE, respectively [164].

In a retrospective study in Boston (USA), 107 consecutive cases referred for possible CS had both CMR and PET [40]. LGE on CMR was present in 91 (85\%), suggesting CS; increased ${ }^{18} \mathrm{FDG}$ uptake on PET was present in $82(76 \%)$. Among 91 with LGE, $60(66 \%)$ had (+) PET [40]. In the UK, 51 consecutive patients with CS had both PET and CMR [39]. Primary composite endpoints were: death; aborted sudden death; sustained VT; CHB; hospital admission for cardiac indication. Secondary endpoints were: fall in LVEF > 10\%; NSVT; other cardiacrelated hospitalization. Overall, 33/51 (65\%) were diagnosed with CS. Sensitivities of PET and CMR were 0.85 and 0.82 respectively. Over a median of 2.2 years, 18 (35\%) experienced ACE. Cardiac RV PET abnormality and myocardial LGE were independent predictors of ACE. The strongest predictor of ACE

Citation: Lynch III JP, Fishbein MC, Bradfield JS, Belperio JA (2021) Cardiac involvement in sarcoidosis: Evolving concepts in diagnosis and treatment. J Cardiovasc Med Cardiol 8(4): 079-102. DOI: https://dx.doi.org/10.17352/2455-2976.000175 
were abnormalities in both PET and CMR [39]. In a prospective study of 61 sarcoidosis patients and 26 healthy volunteers (controls), myocardial LGE was present in 15 sarcoidosis patients but no controls [165]. Additional parameters on CMR (i.e., T1 and T2 mapping) provide additional diagnostic and prognostic information [165-167]. In a sentinel study, CMR were performed in 53 cases of proven extra-cardiac sarcoidosis and 36 healthy controls; 40 patients were followed at a mean interval of $144+/-35$ days [167]. Eighteen sarcoidosis cases were treated with steroids or IA. Myocardial T1 and T2 mapping were increased in sarcoidosis patients compared to controls, and declined (improved) in treated patients $(\mathrm{p}<0.01)$ but not in untreated patients $(\mathrm{p}=0.15)$ [167]. In a recent prospective study (2017-2019), 43 patients (median age 48 years, range 37-54) with proven extra-cardiac sarcoidosis had both PET and CMR simultaneously (hybrid study) to assess the incidence of CS [42]. The authors noted that myocardial LGE was not specific for inflammation and could represent myocardial fibrosis. Hence, newer quantitative mapping techniques to detect early stages of CS (e.g., native T1 and T2 mapping) were applied. Abnormal T1 mapping correlates with myocardial fibrosis or inflammation while $\mathrm{T} 2$ mapping may detect myocardial edema that may occur in the context of myocardial inflammation [42]. Seven patients exhibited diffuse myocardial uptake that was attributed to inadequate dietary preparation and were excluded. In the remaining 36 cases, the following abnormalities were noted on CMR: LGE in 14 (39\%); abnormal T1 mapping in 10 (27\%); abnormal T2 mapping in two (6\%). PET was (+) in 17 (47\%). The authors' defined active CS as LGE $(+)$ and $(+)$ PET; chronic CS if CMR (+) but PET (-); no CS if CMR (-) regardless of PET status. Using these criteria, 13 (36\%) were considered active CS; 5 (14\%) chronic CS; 18 (50\%) no CS. Data are complicated by the fact that $44 \%$ of cases were on steroid therapy and six were on additional IA at the time of study entry [42]. The authors suggested that simultaneous performance of both CMR and PET may be useful to assess prognosis and potential responsiveness to therapy.

Serial CMR may be valuable to follow the course of CS [150], but few long-term follow-up studies have been done. Until recently, CMR could not be done in patients with pacemakers or ICDs. The development of CMR-compatible pacemakers and pacemaker leads [168] made it possible to perform serial CMR even after ICD placement [159]. Importantly, the optimal frequency of repeating scans as well as difficulty in interpretation of studies makes the precise role of radionuclide scans and frequency of tests controversial.

\section{Coronary angiography}

Coronary angiograms are often done in patients with suspected CS to exclude atherosclerotic coronary artery disease. Coronary angiograms are typically normal in CS, but wall motion abnormalities may be observed on ventriculograms [169]. Rarely, vascular filling defects due to granulomatous vasculitis [93] have been described.

\section{What is the role of endomyocardial biopsies?}

Transvenous right ventricular EMB have been used to diagnose CS, particularly when the multisystem disease is not evident $[170,171]$, but sensitivity is low $(19 \%-36 \%)$ $[98,112,172,173]$. The presence of granulomas on histologic samples confirms the diagnosis [67] (Figure 1E). Other histopathologic findings (e.g., myocardial interstitial fibrosis; heart muscle disarrangement and fragmentation; inflammatory mononuclear cell infiltrates) [67,98,171] may support the diagnosis of CS but are nonspecific. In two series of patients with probable CS, the yield of EMB was only $19 \%$ ( 5 of 26) [173] and $22 \%$ ( 4 of 18 ), respectively [172]. In a study of 52 patients with CS seen at one institution, EMB demonstrated CS in 10 of $31(32 \%)$ patients at initial biopsy [98]. The diagnosis was established in seven additional patients by repeat EMB (targeted by cardiac imaging); in 11 patients, the diagnosis of CS was affirmed by sampling ${ }^{18} \mathrm{FDG}$-PET $(+)$ mediastinal lymph nodes. Importantly, the diagnosis of CS was established in four patients after cardiac transplantation and in one at necropsy post SCD. Electrogram characteristics at the biopsy site may predict higher yield. Target sites with abnormal or low electrogram amplitude were associated with good sensitivity (67\%) and specificity in a series of $11 \mathrm{EMB}$ [174].

The low yield of EMB likely reflects sampling error. Cardiac sarcoidosis involves the myocardium in a patchy fashion, particularly in early or mild disease [9]. EMB are obtained mostly from the RV septal wall and apex of the IVS, but NNG more commonly are found in the LV free wall or base of the septum [9]. Although some authors have cited low risk of bleeding complications even with LV EMB [175], most centers rarely perform LV EMB given concern about bleeding given systemic LV pressures $[176,177]$. We do not recommend routine EMB to confirm myocardial involvement provided other objective measures of cardiac dysfunction or abnormality are substantiated (particularly by radionuclide techniques). As will be discussed later, radionuclide and CMR imaging are critical to narrow the diagnosis. In sarcoid patients with cardiac dysfunction, CHB or VA with no alternative etiology should be presumed to have CS, even when EMB are nondiagnostic.

\section{Differential diagnosis and mimics of cardiac sarcoidosis}

The differential diagnosis of CS is complex as the clinical signs (if present) and features on imaging studies overlap with other cardiac disorders. The differential diagnosis includes dilated cardiomyopathy (all causes) $[68,176]$, arrhythmogenic right ventricular cardiomyopathy (ARVC) $[178,179]$, idiopathic giant cell myocarditis (GCM) [180], lymphocytic myocarditis, connective tissue disease [181], vasculitis (including Eosinophilic Granulomatosis with Polyangiitis [182,183] and Takayasu arteritis [184]), amyloidosis [185], dengue fever [186], Chagas disease [187] and other infectious causes (e.g., rheumatic fever, syphilis, fungal infections, tuberculosis). When the clinical presentation is isolated conduction system disease $\left(1^{\text {st }}, 2^{\text {nd }}\right.$, or $3^{\text {rd }}$ degree $\mathrm{HB}$ or $\left.\mathrm{BBB}\right)$, the differential includes age-related conduction system disease, Lyme disease, Brugada syndrome, and myocarditis [178,188].

Is there a role for routine screening for cardiac sarcoidosis?

Mehta, et al. screened 62 ambulatory patients with sarcoidosis for possible cardiac involvement by ECG, Holter

Citation: Lynch III JP, Fishbein MC, Bradfield JS, Belperio JA (2021) Cardiac involvement in sarcoidosis: Evolving concepts in diagnosis and treatment. J Cardiovasc 
monitoring, TTE, and cardiac symptoms (i.e., palpitations, syncope, or pre-syncope) [189]. Those with positive symptoms or screening tests underwent CMR and PET scans. Overall, 24 (39\%) had CS. Not surprisingly, patients with CS had more cardiac symptoms than those without cardiac involvement ( $46 \%$ vs $5 \%$, respectively; $\mathrm{p}<0.001$ ), and were more likely to have abnormal Holters ( $50 \%$ vs $3 \%$, respectively; $p<0.001$ ) and TTE ( $25 \%$ vs $5 \%$, respectively; $\mathrm{p}=0.02)$. Electrophysiological tests (EPS) were done in 17 patients, two of whom had abnormal findings and received an ICD. During almost 2-years of followup, no patients died or had VA that triggered ICD therapy or had heart failure [189]. These authors also evaluated a cohort of 76 patients with biopsy-proven systemic sarcoidosis without cardiac symptoms, but with evidence of CS by PET or CMR 190 All patients underwent programmed electric stimulation (PES) of the ventricle. Sustained VA was induced in eight (11\%) subjects; all eight received an ICD. None of 68 non-inducible subjects received an ICD. All patients were followed for survival and arrhythmic events. Initial LVEF (by TTE) was lower in patients with inducible VA $(36.4 \%$ vs $55.8 \%$, p < 0.05). Over a median follow-up of 5 years, 6 of 8 patients in the group with inducible VA had further episodes of VA or died, compared with one death in the non-inducible group $(p<0.0001)$ [190]. Finnish investigators described nine patients in whom VA [VT or Ventricular Fibrillation (VF)] was the presenting feature of sarcoidosis; EMB were positive in eight [191]. All patients received Anti-Arrhythmic Agents (AAA) and ICDs; eight received high-dose steroids. During follow-up $(50+/-34$ months), five patients underwent appropriate ICD therapies and NSVT episodes were detected in four; two developed incessant VT, treated by catheter ablation. One patient was referred for heart transplant [191]. Dutch investigators recently performed a meta-analysis comprising 1,247 cases of CS over a period of 1.7 to 7 years and found that nine of 664 patients $(1.36 \%)$ with confirmed CS without ICDs died suddenly [164]. Positive LGECMR and $(+)$ Programmed Electric Stimulation (PES) were associated with a relative risk (RR) of 8.6 and 9.1 increased risk of VA, respectively. Further, (+) LGE-CMR and (+) ${ }^{18}$ FDGPET were associated with 6.82- and 3.41-fold increased risk of major ACE, respectively [164]. Since SCD [190,192] can occur even in asymptomatic patients with CS, an ICD should be placed in any patient with CS and a history of serious VA or inducible VT. The course of patients with CS and negative PES (noninducible) appears more favorable, but additional studies are required to determine long-term prognosis and appropriate therapeutic management in this context.

\section{Treatment of cardiac sarcoidosis}

The prognosis of symptomatic CS is not well defined, but mortality rates of untreated CS are high $13,18,68,69$. Numerous publications have cited favorable responses to corticosteroids (steroids) in patients with CS $2,68,169,{ }^{1} 93$ but randomized trials have not been done. Nonetheless, steroids, alone or combined with additional Immunosuppressive Agents (IAs), remain the mainstay of treatment of CS 1,3 .

\section{Anti-arrhythmic Agents and Treatment of Heart Failure}

Anti-Arrhythmic Agents (AAA), diuretics, and medications to treat HF have important adjunctive roles to treat CS and VAs. However, these agents do not eradicate the underlying cause (i.e., inflammation) and breakthroughs (including SCD) can occur even while on AAA $[112,194,195]$. Further, the predictive value of PES-induced VA and guided anti-arrhythmic medical therapy in CS is limited [190,196,197]. Serious (even fatal) VT can develop even in patients in whom VT could not be induced $[72,196]$.

\section{Cardiac ablation}

Cardiac ablation may be efficacious in patients with persistent VT despite medical therapy [191,198-200]. In one study of 42 patients with CS, VT was not controlled despite medical therapy (steroids, AAA) and ICD in nine patients [198]. Radiofrequency ablation resulted in decreased $(n=4)$ or complete $(n=5)$ elimination of VT in all patients. Arrhythmic events decreased from a mean of $271+/-363$ episodes pre-ablation to $4.0+/-9.7$ post-ablation [198]. However, ablation is not consistently effective. Thachhil, et al. reported 14 patients with sustained monomorphic VT (SMVT), mediastinal adenopathy, and abnormal PET in the mid-myocardium consistent with scar +/- inflammation [73]. Mediastinal lymph node biopsies revealed NNG in all 14 patients; 11 (79\%) had tuberculosis (TB). All patients received AAA +/- radiofrequency ablation, yet SMVT recurred in $92 \%$. The addition of disease-specific therapy (for TB or sarcoidosis) abolished further recurrences in $64 \%$. The reduction/disappearance of SMVT correlated with resolution of myocardial inflammation on serial PET-CTs [73].

\section{Implantable Cardioverter Defibrillators (ICDs)}

Implantable cardioverter defibrillators (ICDs) are indicated for patients with CS with a history of VA or AVB, as medical therapy is not consistently effective. In one study, PES was performed in 32 consecutive patients with CS [72]. ICDs were placed in all 12 patients with spontaneous or inducible sustained VT; the other 20 did not receive ICD. All 32 patients were followed for the combined arrhythmic event end-point of appropriate ICD therapies or sudden death. The mean length of follow-up to sustained VA or sudden death was $32+/-30$ months. Five of six patients with spontaneous sustained VA and four of six patients without spontaneous but with inducible sustained VA received appropriate ICD therapy. No patient with an ICD died of primary VA. Among patients with spontaneous or inducible sustained VA, mean survival from first appropriate ICD therapy to death or heart transplant was $60+/-46$ months; only two of 12 patients with ICD died or required heart transplant at study end. Two of 20 patients $(10 \%)$ with neither spontaneous nor inducible sustained VA who did not receive ICD experienced sustained VA or SCD [72].

Schuller, et al. reported 112 cases of CS who received ICDs for prevention of SCD [201]. Over a mean follow-up of 29.2 months, $36(32.1 \%)$ received appropriate therapies for VT. VT storm (> 3 episodes in 24 hours) occurred in 16 (14.2\%) CS subjects; 13 $(11.6 \%)$ received inappropriate therapies. Variables associated with appropriate therapies include LVEF < 55\% (OR 6.52), RV dysfunction (OR 6.73) and, symptomatic HF (OR 4.33) [201]. In patients with recurrent monomorphic VT, ICDs +/- catheter

Citation: Lynch III JP, Fishbein MC, Bradfield JS, Belperio JA (2021) Cardiac involvement in sarcoidosis: Evolving concepts in diagnosis and treatment. J CardiovasC Med Cardiol 8(4): 079-102. DOI: https://dx.doi.org/10.17352/2455-2976.000175 
ablation may have important roles [73] but do not eliminate the need for concomitant anti-inflammatory therapy with steroids or IAs. In one series, seven patients with CS had sustained VT; LVEF was $<45 \%$ in six [112]. All patients received AAA; five received steroids. Two patients had SCD and four had recurrent VT two or more months after initiation of steroid therapy [112]. Given the potential for serious VA and SCD, sarcoid patients with severe VA, advanced AVB, or cardiomyopathy should receive ICDs in addition to medical therapy [112,196,197,202205.] Recommendations and Society Guidelines to treat VA in CS have been published $[102,206]$. Mohsen, et al. reported 33 cases of CS at the University of Louisville (USA) from 20022010,30 of whom received ICDs [207]. Twelve patients (36.3\%) had sustained VT; 11 received appropriate ICD therapies $(36.7 \%)$ and nine received inappropriate shocks $(30.0 \%)$. Patients who received appropriate ICD therapies were younger and had a lower mean LVEF compared to those who did not receive ICD therapies ( $p=0.031$ and 0.041 , respectively) [207]. No other electrophysiological or imaging markers predicted the future occurrence of malignant VA. A multicenter study (13 sites) followed 235 patients who received ICDs for CS [208]. During a mean follow-up of $4.2 \pm 4.0$ years, $85(36.2 \%)$ patients received appropriate ICD therapy (shocks and/or anti-tachycardia pacing) but 57 patients $(24.3 \%)$ received 222 inappropriate shocks; further, 46 adverse events occurred in 41 patients (17.4\%). Patients who received appropriate ICD therapies were more likely to be male $(73.8 \%$ vs $59.6 \%, \mathrm{p}=0.033)$, have a history of syncope $(40.5 \%$ vs $22.5 \%, p=0.004)$, lower LVEF (38.1 vs $48.4 \%, p<0.0001$ ), ventricular pacing on baseline TTE (16.1 vs $2.1 \%, \mathrm{p}<0.0001)$ and a secondary prevention indicator (60.7 vs $24.5 \%, p<0.0001$ ) [208]. Takenaka, et al. reported 188 consecutive cases of CS in two tertiary Japanese hospitals between 1979 and 2020. During a median follow-up of 5.68 years, the primary outcome (i.e., VT/VF or SCD) was met in 44 (23\%) [209]. LVEF $>35 \%$ or $<35 \%$ did not predict the incidence of the primary outcome [209]. These various studies show that patients with CS and AVs are at high risk for VA and SCD, and ICDs may be life-saving [72,112,164,201,207-209]. However, the rate of inappropriate shocks and device complications is not trivial [208].

\section{Corticosteroid therapy for Cardiac Sarcoidosis}

Corticosteroids are the mainstay of therapy for CS and have been associated with clinical improvement and lower mortality rates compared to no treatment, but randomized trials have not been done. In 2001, Yazali, et al. described 95 Japanese patients with CS seen between 1984 and $1996{ }^{18}$. The diagnosis of CS was made at necropsy in 20 cases, none of whom had been treated with steroids. All 75 in whom the diagnosis was established antemortem were treated with steroids. During a mean follow-up of 68 months, 29 of 75 treated patients (39\%) died of HF and 11 (15\%) died suddenly. Five-year survival rates (by Kaplan-Meier analysis) were $75 \%$ in the steroid-treated cases compared to only $10 \%$ in (untreated) autopsy cases. There were no significant differences in survival curves of patients treated with a high initial dose $(>30 \mathrm{mg}$ ) or a low initial dose $(<30$ $\mathrm{mg}$ ) of prednisone [18]. Another Japanese study of 195 cases of sarcoidosis treated with steroids cited a lower response rate to steroids (48\%) among CS cases compared to $>70 \%$ response when sarcoidosis involved only non-cardiac sites [210]. The extent and severity of the disease may influence therapeutic responsiveness. Kato, et al. described 40 cases with CS, 20 of whom had AVB but normal cardiac function (LVEF > 50\%) [193]. In the subset of 20 patients with normal LV function, seven were treated with steroids; 13 were not treated. During a mean observation period of $79.4+/-39.9$ months, none of seven treated patients died whereas two of $13(15.4 \%)$ untreated patients died [193]. AVB resolved in four of seven steroidtreated patients but did not resolve in any of 13 untreated patients $(p<0.05)$. While LVEF did not differ significantly between the treated and untreated groups at the time of initial evaluation (66.7\% vs. $60.5 \%)$, LVEF declined in the untreated cases during follow-up (LVEF $37.6+/-17.3 \%$ ), but not in the treated group (LVEF $62.1+/-4.4 \%$; $<<0.005$ ) [193]. At the initial assessment, VT was not present in any patient in either group. During follow-up, VT occurred in only one of seven treated cases $(14.3 \%)$ compared to eight of 13 untreated cases $(61.5 \% ; p<0.05)$ [193]. In another study, 31 Japanese subjects with CS and frequent PVCs (> 300/day) were followed: 14 had NSVT [211]. All cases were treated with prednisone (initial dose $30 \mathrm{mg}$ /day). There was no difference in the number of PVCs or incidence of NSVT before or after steroid therapy. However, in patients with LVEF > 35\%, the number of PVCs per 24 hours declined from 1,820 to 742 and the prevalence of NSVT fell from $41 \%$ to $6 \%$. Cases with LVEF > $35 \%$ had a significantly higher prevalence of cardiac $\mathrm{Ga}^{67}$ uptake compared to cases with LVEF $<35 \%$. This suggests that steroids may be effective in the early inflammatory phase, but not in the late stages of CS [211]. These investigators subsequently reported 15 patients with CS with advanced or complete AVB; all were treated with prednisone (initial dose $30 \mathrm{mg} /$ day) after placement of an ICD [212]. During a mean follow-up of 7.1 years, AVB resolved to normal or $1^{\text {st }}$ degree $\mathrm{AVB}$ in seven cases $(47 \%)$. In the responder group, advanced AVB did not recur and LVEF was higher (69.4\%) compared to non-responders (LVEF 44.1\%) [212]. Nagai, et al. reported 83 consecutive cases of CS in Japan from 1990-2012 with a mean follow-up of $7.6+/-4.4$ years; 67 $(81 \%)$ were treated with steroids; $2 \%$ received other IAs [24]. There were no differences in frequency of AVB, VT, or HF at the time of diagnosis in treated versus untreated cases. The mean initial daily dose of prednisone was $29.5 \mathrm{mg}$; the median duration of steroid therapy was $7.1+/-4.4$ years. Steroid therapy was associated with fewer hospitalizations for $\mathrm{HF}$ and an increase in LVEF at follow-up compared to untreated patients although there were no differences in cardiac deaths or symptomatic arrhythmias between groups [24]. In another study by these investigators, the impact of discontinuing steroids was evaluated in a cohort of 61 consecutive cases of CS treated with steroids and followed for a median of 9.9 years [25]. Steroids were discontinued in 12 patients following clinical improvement; none of the 12 who discontinued steroids were taking other IAs. After discontinuing steroids, LVEF fell and five of $12(41.7 \%)$ died of cardiac causes; by contrast, cardiac death occurred in only six of $49(12.2 \%)$ who continued steroid therapy. In summary, discontinuation of steroids was associated with increased cardiac mortality $(\mathrm{p}=0.035)$ and greater decline in LVEF compared to continuation of steroids $(\mathrm{p}=0.037)[25]$

Citation: Lynch III JP, Fishbein MC, Bradfield JS, Belperio JA (2021) Cardiac involvement in sarcoidosis: Evolving concepts in diagnosis and treatment. J Cardiovasc Med Cardiol 8(4): 079-102. DOI: https://dx.doi.org/10.17352/2455-2976.000175 
A retrospective study at Albany Medical Center (USA) (2001-2014) assessed the impact of "early" (within 30 days of diagnosis of CS) steroid therapy in a cohort of 30 cases of CS [5]. Steroid therapy was initiated in 27 cases ("early", i.e., within 30 days of onset of symptoms in 23 cases) and "delayed" (i.e., > 30 days) in four cases; three were not treated. While the dosage of steroids varied, the "vast majority" received prednisone 30$40 \mathrm{mg}$ daily for at least one month, followed by a gradual taper. ICDs were placed in 13/14 (93\%) with VA. Clinical endpoints included mean LVEF, VA, and advanced (grade 2 or 3 ) AVB. At entry, 14 (47\%) had LV systolic dysfunction; 14 (47\%) had VA; five $(17 \%)$ had advanced AVB. Among 14 cases who received "early" steroids, LVEF improved in nine (from the mean of $25 \%$ to $46 \%, \mathrm{p}<0.001)$. Among five receiving "delayed" or no steroid therapy, LVEF did not improve ( $41 \%$ to $37 \%$, p = 0.47). Further, 8/11 (72\%) with VA who received "early" steroids had no recurrence whereas all three with "delayed" steroids had recurrent VA. Advanced AVB resolved in two of three in the early steroid group and persisted in both patients receiving delayed steroids. Despite the small sample size, these data suggest that early treatment with steroids may improve clinical outcomes [5]. Japanese investigators retrospectively analyzed $15 \mathrm{CS}$ patients with complete AVB treated with steroids [213]. An "early" diagnosis (within 1 year) was made in 10 cases; the diagnosis of CS was "late" (> 1 year) in five. Interestingly, extra-cardiac sarcoidosis was diagnosed in $60 \%$ of "early" and $0 \%$ in the "late" group ( $p=0.044)$; further, TTE was abnormal in 70\% of "early" and $0 \%$ in "late" cases (p = 0.0256). Importantly, after steroid therapy, LVEF and brain natriuretic peptide (BNP) significantly improved in the early compared to late group [213]. This supports the importance of early initiation of therapy to optimize outcomes. A recent update by these investigators reported 24 patients with CS and complete or advanced AVB receiving steroid therapy [214]. Univariate Cox analysis demonstrated that LVEF (HR 1.07, p = 0.016), the shorter interval from recognizing AVB to start of therapy (HR 0.98, < 0.001), and serum lysozyme levels (HR $1.51, \mathrm{p}=0.013$ ) were significantly associated with resolution of AVB [214]. Sadek, et al. performed a meta-analysis of 10 publications that evaluated steroid treatment of CS [215]. There were no randomized trials and all publications were considered of "poor to fair quality". Among 57 patients with AV conduction disease treated with steroids, $47.4 \%$ improved whereas none of 16 untreated patients improved [215].

Despite the lack of randomized trials, extensive clinical experience strongly supports aggressive treatment with steroids for clinically-evident CS $[1,3,27,216]$. However, data are too limited to comment on the dose or appropriate duration of steroid therapy and/or when to initiate IA (or which agent). In the following section, we discuss the role of IA (typically together with steroids) to treat CS.

\section{Therapy for CS: Role of Immunosuppressive Agents} (IAs)

Failures (including SCD) may occur in patients with CS despite high dose steroids [199,200]. IA has an important adjunctive role in CS, not only for steroid-sparing properties but may also enhance efficacy [29,30]. A variety of IA and Disease Modifying Anti-Rheumatic Agents (DMARA) have been used to treat pulmonary and extra-pulmonary sarcoidosis (including steroid-recalcitrant cases) [27,30,31,217-221]. Although randomized trials are lacking, methotrexate (MTX) has been the IA most often use to treat CS $[26,222]$ and recommendations regarding its use have been promulgated by WASOG [26]. An international retrospective cohort study evaluated 200 sarcoidosis patients who had completed $>$ one year of therapy with either MTX $(n=145)$ or azathioprine (AZA) $(n=55)$ [222]. Both agents had similar steroid-sparing effects and pulmonary function tests improved similarly in both treatment groups. There were more infections in the AZA group (34.6\%) vs $18.1 \%$ in the MTX group, $\mathrm{p}=0.01$ but there were no differences in other adverse effects [222]. Experience with IA and DMARA to treat CS is limited to retrospective series with different agents, doses, and duration of therapy. Gallegos, et al. recently reviewed 23 publications comprising 480 cases of CS treated with a range of DMARA [29]. The most commonly used non-steroidal agents were MTX and infliximab (IFX). The use of DMARA was steroid-sparing, with a reduction in the maintenance steroid dose [29]. We discuss a few major studies of IA use in CS (usually in tandem with steroids) below.

In a retrospective French study, 39 patients with CS were treated with steroids (initial dose prednisone $\sim 1 \mathrm{mg} / \mathrm{kg} /$ day); 13 also received another IA [27]. All had extra-cardiac involvement. The average duration of therapy was 43 months (range 6-168 months). During long-term follow-up (average 58 months), $87 \%$ improved, and 54\% were presumed cured; no patient died suddenly. Two patients worsened, one of whom did not receive pharmacological therapy. During follow-up, nine patients relapsed. At the time of relapse, prednisone dose was $<10 \mathrm{mg} /$ day in five patients; prednisone had been discontinued in three patients. All nine relapses were treated with steroids (alone, or combined with IA); six were cured and three showed clinical and laboratory improvement [27]. Data are insufficient to assess the impact of IA or efficacy of specific IA [27]. In a subsequent retrospective study, these investigators followed 59 cases of CS for a median of 60 months [28]. The median age at initial cardiac signs was 42 years. First-line therapy was steroids alone $(n=24)$ or combined with IA $(n=35)$. Overall, $47 / 59(80 \%)$ recovered; 12 remained stable or worsened [28]. Recovery rates were not significantly different in those treated with steroids alone (75\%) compared to steroids plus IA ( $83 \%)$. Five ( $9 \%$ ) died during follow-up; two deaths were attributed to CS. Overall one- and 5-year survival rates were $98 \%$ and $92 \%$, respectively ${ }^{28}$. A retrospective study from the University of Cincinnati (USA) reported 73 cases of "probable or highly probable" CS [4] (based upon 2014 criteria per WASOG) [102] over a 6-year period. All had extra-cardiac involvement, most commonly lung (94.5\%). Presenting features included: reduced LVEF (54.8\%); VT (35.6\%); advanced AVB (19.2\%). Cases were initially treated with prednisone $(30 \mathrm{mg} /$ day $)$ plus IAs [most commonly MTX ( $n=47)$, AZA ( $n=23)$; mycophenolate mofetil (MMF) ( $n=9)$; hydroxychloroquine $(n=11)$; other $(n=11)$. ICD's were placed in $59 \%$. Cases with persistent disease after 6 months of therapy were treated with additional cytotoxic agents or biological agents [e.g., IFX, rituximab (RITUX)] [4].

Citation: Lynch III JP, Fishbein MC, Bradfield JS, Belperio JA (2021) Cardiac involvement in sarcoidosis: Evolving concepts in diagnosis and treatment. J Cardiovasc Med Cardiol 8(4): 079-102. DOI: https://dx.doi.org/10.17352/2455-2976.000175 
Cases were followed for a median of 8.8 years. Five- and 10year survival rates were $95.5 \%$ and $93.4 \%$, respectively. At follow-up, $10(13.7 \%)$ either had heart transplant $(n=3)$ or died $(n=7)$ from sarcoidosis. Multivariate analysis found no association between the type of immunomodulatory therapy and survival. However, Cox regression analysis showed that age $>46$ years and lack of implanted pacemaker or defibrillator were the only independent predictors of mortality [4]. Finnish investigators reported 110 adults with CS seen between 19982012 [23]. Steroids were given to 102 subjects; the eight untreated cases were diagnosed at necropsy or via cardiac explant at transplant. Additional IA used included: AZA ( $n=50)$; MTX ( $n=6), \operatorname{MMF}(n=2)$; cyclosporine $(n=2)$, IFX $(n=1)$. LVEF was impaired $(<50 \%)$ in 65 patients at diagnosis $(59 \%)$ and showed no overall change over 12 months of steroid therapy. During a median follow-up of 6.6 years, 10/102 (9.8\%) died of cardiac causes; $11(10.8 \%)$ underwent heart transplant; six $(5.5 \%)$ died of non-cardiac causes. Kaplan Meier estimates for $1-, 5^{-}$, and 10 -year survival were $97 \%, 90 \%$, and $83 \%$, respectively. Heart failure at presentation was associated with a 10 -year transplant-free survival of only $52.5 \%(p=0.0001)$. Among patients treated with steroids, transplant-free survival was similar among those receiving initial doses of prednisone of $<60$ or $>60 \mathrm{mg}$ daily ( $\log$ rank $\mathrm{p}=0.561$ ) and did not differ from those receiving steroids within 6 months of the onset of symptoms compared to $>6$ months $(\log$ rank $\mathrm{p}=0.867)$. Data were inadequate to assess the impact of IA on outcomes [23]. A retrospective study from Paris (2012-2016) reported 36 cases of CS; 24 were treated with steroids alone and 12 received steroids plus an IA [(AZA $(\mathrm{n}=5) ; \operatorname{MTX}(\mathrm{n}=5)$; cyclophosphamide (CYC) $(n=2)$ ] [44]. At a median follow-up of 3.6 years, $13(36.1 \%)$ had a cardiac relapse [i.e., reduced $\operatorname{LVEF}(n=4) ; \operatorname{HB}(n=2)$; atrial tachycardia $(\mathrm{n}=1) ; \mathrm{VT}(\mathrm{n}=1) ; \operatorname{SCD}(\mathrm{n}=1)]$. Relapse rate was $45.8 \%$ in the steroid alone group versus $16.7 \%$ in steroids + IA $(\mathrm{p}=0.048)$. These data support combination therapy with steroids + IA. Other IA (e.g., leflunomide [223,224] and MMF [225,226]) have been used with anecdotal successes in pulmonary and extra-pulmonary sarcoidosis in small trials. In one retrospective study in neurosarcoidosis comparing MTX with $M M F$, relapses were more common with MMF, and time to relapse was shorter with MMF compared to MTX [226]. Given the paucity of data, the optimal agent or agents to treat CS, and appropriate duration of therapy, have not been elucidated.

\section{Tumor Necrosis Factor alpha (TNF-a) antagonists}

$\mathrm{TNF}-\alpha$ antagonists are considered third-line agents used to treat CS, usually in cases failing or experiencing adverse effects from steroids or IA $[32,227]$. Interestingly, early placebocontrolled randomized trials in non-sarcoid populations with Congestive Heart Failure (CHF) found that TNF- $\alpha$ antagonists showed no benefit $[228,229]$ and one study suggested harm [228]. These trials were stopped due to lack of benefit (i.e., clinical status, death, or hospitalization for CHF) and a black box warning against $\mathrm{TNF}-\alpha$ antagonists exists for patients with CHF. However, TNF- $\alpha$ is a key mediator of inflammation and granuloma formation in sarcoidosis [30], so there is a strong rationale to use TNF- $\alpha$ antagonists in cases of sarcoidosis failing standard therapy. Importantly, several non-randomized trials in pulmonary [230] and extra-pulmonary sarcoidosis refractory to steroids or IA reported favorable responses to $\mathrm{TNF}-\alpha$ antagonists [particularly infliximab and adalimumab (ADA)] [32,227,231-233]. A six-center trial in the USA treated 66 cases with neurosarcoidosis with IFX; favorable clinical responses occurred in $77 \%$, including complete recovery in $28.8 \%$ [232]. In a multicenter trial in France, 132 patients with sarcoidosis (multiple sites) refractory to standard therapy received antiTNF- $\alpha$ therapy (IFX in 91\%) [234]. Clinical responses (complete or partial) occurred in $64 \%$ but adverse effects were common $(52 \%)$ including infections in $36 \%$. There was no difference in outcomes between anti-TNF- $\alpha$ therapy alone versus antiTNF- $\alpha$ therapy combined with another IA [234]. Although data regarding the use of TNF- $\alpha$ antagonists in CS are limited, a multicenter retrospective study in the USA reported 38 cases of CS (mean age 49.9 years) treated with IFX $(n=30)$ or ADA $(n=8)$ [34]. Increased cardiac uptake of ${ }^{18} \mathrm{FDG}$ was present in $86 \%$ pre anti-TNF - $\alpha$ therapy and resolved or improved in $73 \%$ post treatment. The daily dose of prednisone decreased from the time of initiation of TNF- $\alpha$ antagonists from $21.7 \mathrm{mg}$ to 7.2 $\mathrm{mg}$ at 12 months and LVEF remained stable ( 45.0 to $47.0 \%, \mathrm{p}=$ $0.10)$. Infections (some serious) occurred in eight patients (21\%) [34]. In another study of 36 consecutive cases of CS refractory to standard therapy, IFX was associated with improvement in at least one of three outcome categories in 26 (67\%) [32]. Of 16 patients with serial dysrhythmias, there was a trend to reduce VT from $32 \%$ at baseline to $22 \%$ at 6 months and $19 \%$ at 12 months $(p=0.07)$ [32]. Serial LVEF in $25 \mathrm{pts}$ demonstrated no change from baseline (41\%) to 6 months of therapy (42\%) [32]. In a single center study in the Netherlands, 22 patients with CS received IFX between 2016-2019 (dose $5 \mathrm{mg} / \mathrm{kg}$ at week 0, 2 , and subsequently every 4 weeks) [33]. At a mean follow-up of 18.9 months ( 6 to 44 months), 18/22 (82\%) had responded and median SUVmax on ${ }^{18}$ FDG-PET decreased (improved) from 5.2 to 2.3 ( $p=0.015)$. None had worsening HF. No serious side effects were noted [33]. Rosenthal, et al. reported 28 cases of CS followed for a mean of 4.1 years [231]. Following initial treatment with steroids and MTX, 19 patients with persistently active CS or intolerance to MTX received ADA. Adalimumab was associated with improvement $(84 \%)$ or resolution $(63 \%)$ of ${ }^{18} \mathrm{FDG}$ uptake [231]. Data regarding other TNF- $\alpha$ antagonists are limited. However, etanercept was ineffective as therapy for progressive pulmonary sarcoidosis [235] or chronic ocular sarcoidosis [236]. Further, etanercept has a higher incidence of paradoxical sarcoid-like reactions compared to other TNF$\alpha$-antagonists and is not recommended [30]. While IFX may be the most efficacious agent in this class, ADA can be substituted in patients experiencing adverse effects with IFX [237].

\section{Other biological agents}

Case reports [238] and small series have cited beneficial responses to rituximab [239] and Janus kinase (JAK) inhibitors in patients with refractory extra-pulmonary sarcoidosis $[240,241]$. These data are interesting, but data are extremely limited and these agents should be considered experimental or for consideration only when failing other existing therapies. Similarly, the role of inhibitors to certain cytokines and chemokines such as interleukin (IL)-6, IL12, IL17 [30] and

Citation: Lynch III JP, Fishbein MC, Bradfield JS, Belperio JA (2021) Cardiac involvement in sarcoidosis: Evolving concepts in diagnosis and treatment. J Cardiovasc Med Cardiol 8(4): 079-102. DOI: https://dx.doi.org/10.17352/2455-2976.000175 
others are worthy of future consideration but will not be further discussed in this review.

\section{Our approach to the treatment of cardiac sarcoidosis}

Given the complexity of CS, and possible SCD due to AV or $\mathrm{CHB}$, a multidisciplinary approach including experienced cardiac electrophysiologists, experts in cardiomyopathy, and experts in sarcoidosis and immunosuppressive therapy is critical. Cardiologists manage HF, fluid status, arrhythmias, need for ICD or AAA, etc. while pulmonologists with expertise in CS and IA manage the steroid and immunosuppressive therapy. Appropriate use of diuretics and agents to treat HF and arrhythmias are important but do not eliminate the need for anti-inflammatory therapy with steroids +/- IA. Our therapeutic anti-inflammatory approach in patients with proven or suspected myocardial sarcoidosis is based in large part upon extensive clinical experience by one of us (JPL) in sarcoidosis (both cardiac and non-cardiac) [95,242-245] as well as expertise in immunosuppressive agents for inflammatory systemic disorders (including but not limited to sarcoidosis) $[246,247]$. Despite the lack of randomized trials, the evidence that steroids (with or without IA) have been associated with clinical responses and fewer ACEs in CS compared to no treatment is readily apparent. Further, discontinuing therapy after a favorable response can be dangerous, as relapses (even fatalities) may occur. For a patient with active or presumed active CS, we initiate treatment with steroids. Symptomatic patients or those with serious VA or HF typically receive a 3-day pulse of intravenous methylprednisolone (500-1,000 mg daily), followed by prednisone $40 \mathrm{mg} /$ day for a minimum of 4 weeks. Patients without severe VA or HF are usually treated with prednisone alone for the first several weeks. After 4-6 weeks, we add an IA [most often MTX (15-25 mg once weekly) or AZA (100-150 mg daily)]. Prednisone is usually tapered to $30 \mathrm{mg}$ after 4 weeks, and gradually to a maintenance dose of $10 \mathrm{mg}$ by 6 months. The rate of CS taper is variable depending upon the clinical status and the presence or absence of adverse effects. The duration of therapy depends upon the individual case, but we typically maintain low dose prednisone (5-10 mg daily) with an IA for a minimum of 2-3 years since relapses can be life-threatening and may cause permanent damage. Clinical relapses of CS require re-treatment with high dose steroids and/or IA.

For follow-up, serial TTE (to assess cardiac function and LVEF) and BNP are done no less often than every 3 months. Interrogation of pacemakers every 3 months is recommended for patients with ICDs.The value of serial radionuclide studies "routinely" after six months is not clear, although we believe PET and/or CMR may be invaluable in cases with persistent or worsening symptoms.

\section{Surgical options}

Surgical resection of ventricular aneurysms may be necessary for the management of refractory VT [248-250]. Massive or recurrent pericardial effusions refractory to medical therapy may require pericardiectomy or pericardial window $[69,85]$.

\section{Cardiac transplantation}

Cardiac transplantation should be considered for patients with severe intractable heart failure refractory to therapy [251-258]. In a review of 19 patients with CS who had a cardiac transplant, the five-year post-transplant survival rate was $79 \%$, comparable to $83 \%$ five-year survival among recipients transplanted for other indications [251]. No patient had recurrent sarcoidosis in the cardiac allograft. Zaidi, et al. examined outcomes of 65 heart transplant recipients with CS from 1987 to 2005 in the USA national United Network for Organ Sharing (UNOS) database [253]. In that study, one- and five-year survival rates were $87.7 \%$ and $80.5 \%$ compared to $84.5 \%$ and $70 \%$ survival among heart transplant recipients without sarcoidosis [253]. A recent meta-analysis cited similar one- and 5-year survival rates post heart transplant for CS compared to other etiologies, although survival rates were statistically better in patients with CS after 5 years [259]. Rosenthal, et al. reported 12 patients with CS who received heart transplants and 28 heart transplant recipients without sarcoidosis; lung allograft rejection was less common in the CS group $(17 \%$ vs $68 \%, \mathrm{p}=0.006)$. None of the 12 sarcoid patients died or developed recurrent CS [260]. Recurrent sarcoidosis has been described in cardiac allografts [256,261-264], but is uncommon $(<10 \%)$ [251,252,259] and may respond to intensification of corticosteroids [265].

\section{Summary and key points (Table I)}

- The diagnosis of CS may be difficult, as endomyocardial biopsies are positive in $<40 \%$ of cases.

- A probable diagnosis of CS can be made when characteristic clinical features [e.g., arrhythmias (especially VA), AVB, or cardiomyopathy are present, together with histologically confirmed sarcoidosis in other organs]

- Radionuclide scans (PET and CMR) are important to support the diagnosis and in some cases may be useful to assess resolution or relapse of disease but appropriate monitoring remains controversial.

- Treatment requires a multidisciplinary team including cardiologists with expertise in arrhythmias, heart failure, and cardiomyopathy, as well as individuals with extensive experience in sarcoidosis and the use of immunosuppressive agents.

- Therapy for specific cardiac events (arrhythmias, cardiac failure) is critical, but are insufficient since those therapies do not influence granulomatous inflammation, the driver of the cardiac manifestations.

- Implantable cardioverters and defibrillators (ICDs) should be placed in any patient with CS with severe VA, heart block, or severe heart failure and may be lifesaving.

- Although randomized, placebo-controlled trials have not been done, extensive clinical studies have shown 
Table 1: Diagnosis of Cardiac Sarcoidosis.

\section{Histological Diagnosis}

- Myocardial biopsy showing non-necrotizing granuloma with negative stains and smears for other etiologies (mainly infectious). Highly specific but sensitivity low (17-36\%)

- Extra-cardiac biopsy showing non-necrotizing granulomas (particularly in lung, mediastinal and hilar lymph nodes) with alternative etiologies (particularly infections) excluded. Supports but does not confirm the diagnosis of cardiac sarcoidosis.

\section{Clinical features (common but nonspecific)}

- Unexplained arrhythmias (particularly ventricular tachycardia and/or ventricular fibrillation but also atrial arrhythmias)

- Unexplained atrioventricular block (particularly Mobitz type 2 or $3^{\text {rd }}$ degree)

- Younger age (<65 years); absence of coronary artery disease

\section{Laboratory features:}

- Transthoracic echocardiogram: Regional abnormal wall motion abnormalities, global or focal hypokinesis or dyskinesia, chamber enlargement, ventricular dilatation or hypertrophy, ventricular wall thickening or thinning, depressed ejection fraction). Common but completely nonspecific.

- Serum angiotensin converting enzyme levels (low sensitivity since SACE correlates with total body granuloma burden and is usually not elevated in CS).

\section{Radiographic features}

- High resolution computed tomographic (HRCT) scan: Pulmonary micronodules, peribronchiolar and upper lung field predominance, with or without reticular alveolar opacities may support the diagnosis of sarcoidosis. In this context, transbronchial lung or mediastinal lymph node biopsies may reveal NNG.

\section{Radionuclide scans}

- Gallium ${ }^{67}$-citrate and thallium ${ }^{201}$ scans: Perfusion defects that improve or resolve with exercise or dipyridamole (moderately sensitive, but these scans are primarily of historical interest and have been replaced by PET and CMR scans.

${ }^{18}$ Fluorodeoxyglucose $\left({ }^{18} \mathrm{FDG}\right)$ positron emission tomography (PET) scans: Increased ${ }^{18} \mathrm{FDG}$-avidity in myocardium (diffuse, focal, or focal on diffuse) +/- perfusion defects or wall motion abnormalities. Extracardiac foci of ${ }^{18} \mathrm{FDG}$-avidity in lung, mediastinal or hilar lymph nodes or other sites support the diagnosis of sarcoidosis. Changes in ${ }^{18} \mathrm{FDG}$ avidity may reflect increases or decreases in inflammation.

- Gadolinium cardiac magnetic resonance (MRI): Late (delayed) enhancement of gadolinium in myocardium not in distribution of prior myocardial infarction. Sites of activity may be patchy or focal with the most common affected areas being LV free wall, interventricular septum, and/or papillary valves. May have increased signal intensity in T1 and T2-weighted images.

benefits with corticosteroid therapy, either alone or with other anti-inflammatory agents (particularly immunosuppressive agents).

- Dual drug therapy (with steroids and an IA) is logical, given the steroid-sparing effects of IA as well as enhanced efficacy in some cases.

- Duration of therapy has not been well established, although long-term ( $>2-3$ years, possibly indefinite therapy) may be required.

- Heart transplantation is an option for CS cases with severe intractable heart failure or arrhythmias despite medical therapy, with results comparable or better than non-sarcoid cases.

\section{References}

1. Sayah DM, Bradfield JS, Moriarty JM, Belperio JA, Lynch JP (2017) Cardiac Involvement in Sarcoidosis: Evolving Concepts in Diagnosis and Treatment. Semin Respir Crit Care Med 38: 477-498. Link: https://bit.ly/309hJhl

2. Ayyala US, Nair AP, Padilla ML (2008) Cardiac sarcoidosis. Clin Chest Med 29 493-508.Link: https://bit.ly/3Gp4rx4

3. Nunes $H$, Freynet $O$, Naggara N, Soussan M, Weinman P, et al. (2010) Cardiac sarcoidosis. Semin Respir Crit Care Med 31: 428-441. Link: https://bit.ly/3ozTIPN

4. Zhou Y, Lower EE, Li HP, Costea A, Attari M, et al. (2017) Cardiac Sarcoidosis: The Impact of Age and Implanted Devices on Survival. Chest 151: 139-148. Link: https://bit.ly/3y3mtSx

5. Padala SK, Peaslee S, Sidhu MS, Steckman DA, Judson MA (2017) Impact of early initiation of corticosteroid therapy on cardiac function and rhythm in patients with cardiac sarcoidosis. Int J Cardiol 227: 565-570. Link: https://bit.ly/3dwpAZJ
6. Kinney EL, Jackson GL, Reeves WC, Zelis R (1980) Thallium-scan myocardia defects and echocardiographic abnormalities in patients with sarcoidosis without clinical cardiac dysfunction. An analysis of 44 patients. Am J Med 68 497-503. Link: https://bit.ly/3DA905C

7. Fahy GJ, Marwick T, McCreery CJ, Quigley PJ, Maurer BJ (1996) Doppler echocardiographic detection of left ventricular diastolic dysfunction in patients with pulmonary sarcoidosis. Chest 109: 62-66. Link: https://bit.ly/31Dp4GC

8. Perry A, Vuitch F (1995) Causes of death in patients with sarcoidosis. morphologic study of 38 autopsies with clinicopathologic correlations. Arch Pathol Lab Med 119: 167-172. Link: https://bit.ly/3pBfWdN

9. Roberts WC, McAllister HA Jr, Ferrans VJ (1977) Sarcoidosis of the heart. A clinicopathologic study of 35 necropsy patients (group 1) and review of 78 previously described necropsy patients (group 11). Am J Med 63: 86-108. Link: https://bit.ly/3du08E7

10. Silverman KJ, Hutchins GM, Bulkley BH (1978) Cardiac sarcoid: clinicopathologic study of 84 unselected patients with systemic sarcoidosis. Circulation 58: 1204-1211. Link: https://bit.ly/3dB6IZm

11. Virmani R, Bures JC, Roberts WC (1980) Cardiac sarcoidosis; a major cause of sudden death in young individuals. Chest 77: 423-428. Link: https://bit.ly/30530Em

12. Bagwan IN, Hooper LV, Sheppard MN (2011) Cardiac sarcoidosis and sudden death. The heart may look normal or mimic other cardiomyopathies. Virchows Arch 458: 671-678. Link: https://bit.ly/3y4Vx4N

13. Matsui $\mathrm{Y}$, Iwai K, Tachibana T, Fruie T, Shigematsu N, et al. (1976) Clinicopathological study of fatal myocardial sarcoidosis. Ann N Y Acad Sci 278: 455-469. Link: https://bit.ly/3y3Vk1

14. Hu X, Carmona EM, Yi ES, Pellikka PA, Ryu J (2016) Causes of death in patients with chronic sarcoidosis. Sarcoidosis Vasc Diffuse Lung Dis 33: 275-280. Link: https://bit.ly/33cvqxx

15. Stewart RE, Graham DM, Godfrey GW, Friedman HZ, Das SK, et al. (1988) Rapidly progressive heart failure resulting from cardiac sarcoidosis. Am Heart J 115: 1324-1326. Link: https://bit.ly/3dyBhzc

Citation: Lynch III JP, Fishbein MC, Bradfield JS, Belperio JA (2021) Cardiac involvement in sarcoidosis: Evolving concepts in diagnosis and treatment. J Cardiovasc Med Cardiol 8(4): 079-102. DOI: https://dx.doi.org/10.17352/2455-2976.000175 
16. Tavora F, Cresswell N, Li L, Ripple M, Solomon C, et al. (2009) Comparison of necropsy findings in patients with sarcoidosis dying suddenly from cardiac sarcoidosis versus dying suddenly from other causes. Am J Cardiol 104: 571 577. Link: https://bit.ly/3rQI2ob

17. Fleming HA, Bailey SM (1981) Sarcoid heart disease. J R Coll Physicians Lond 15: 245-246, 249-253. Link: https://bit.ly/3Go1897

18. Yazaki Y, Isobe M, Hiroe M, Morimoto S, Hiramitsu S, et al. (2001) Prognostic determinants of long-term survival in Japanese patients with cardiac sarcoidosis treated with prednisone. Am J Cardiol 88: 1006-1010. Link: https://bit.ly/3GsPV7d

19. Zoneraich S, Gupta MP, Mehta J, Zoneraich O, Wessely Z (1974) Myocardial sarcoidosis presenting as acute mitral insufficiency. Chest 66: 452-454. Link: https://bit.ly/33cfY4s

20. Gozo EG Jr, Cosnow I, Cohen HC, Okun L (1971) The heart in sarcoidosis. Chest 60: 379-388. Link: https://bit.ly/3pwptTm

21. Bashour FA, McConnell T, Skinner W, Hanson M (1968) Myocardial sarcoidosis Dis Chest 53: 413-420. Link: https://bit.ly/3ECrMuE

22. Porter GH (1960) Sarcoid heart disease. N Engl J Med 263: 1350-1357. Link: https://bit.ly/3IOezHF

23. Kandolin R, Lehtonen J, Airaksinen J, Vihinen T, Miettinen H, et al. (2015) Cardiac sarcoidosis: epidemiology, characteristics, and outcome over 25 years in a nationwide study. Circulation 131: 624-632. Link: https://bit.ly/3EEkJ4s

24. Nagai $T$, Nagano N, Sugano $\mathrm{Y}$, Asaumi $\mathrm{Y}$, Aiba T, et al. (2015) Effect of Corticosteroid Therapy on Long-Term Clinical Outcome and Left Ventricular Function in Patients With Cardiac Sarcoidosis. Circ J 79: 1593-1600. Link: https://bit.ly/3owWgZq

25. Nagai $T$, Nagano $N$, Sugano $Y$, Asaumi $Y$, Aiba T, et al. (2016) Effect of Discontinuation of Prednisolone Therapy on Risk of Cardiac Mortality Associated With Worsening Left Ventricular Dysfunction in Cardiac Sarcoidosis. Am J Cardiol 117: 966-971. Link: https://bit.ly/3y47lim

26. Cremers JP, Drent M, Bast A, Shigemitsu H, Baughman RP, et al. (2013) Multinational evidence-based World Association of Sarcoidosis and Other Granulomatous Disorders recommendations for the use of methotrexate in sarcoidosis: integrating systematic literature research and expert opinion of sarcoidologists worldwide. Curr Opin Pulm Med 19: 545-561. Link: https://bit.ly/3rNzGxO

27. Chapelon-Abric C, de Zuttere D, Duhaut $P$, Veyssier $P$, Wechsler B, et al. (2004) Cardiac sarcoidosis: a retrospective study of 41 cases. Medicine (Baltimore) 83: 315-334. Link: https://bit.ly/3pG0eOA

28. Chapelon-Abric C, Sene D, Saadoun D, Cluzel P, Vignaux O, et al. (2017) Cardiac sarcoidosis: Diagnosis, therapeutic management and prognostic factors. Arch Cardiovasc Dis 110: 456-465. Link: https://bit.ly/3y47SGu

29. Gallegos C, Oikonomou EK, Grimshaw A, Gulati M, Young BD, et al. (2021) Nonsteroidal treatment of cardiac sarcoidosis: A systematic review. Int $\mathrm{J}$ Cardiol Heart Vasc 34: 100782. Link: https://bit.ly/31H1OYe

30. Obi ON, Lower EE, Baughman RP (2021) Biologic and advanced immunomodulating therapeutic options for sarcoidosis: a clinical update. Expert Rev Clin Pharmacol 14: 179-210. Link: https://bit.ly/306Mm7t

31. Uthman I, Touma Z, Khoury M (2007) Cardiac sarcoidosis responding to monotherapy with infliximab. Clin Rheumatol 26: 2001-2003. Link: https://bit.ly/3oA0CPj

32. Harper LJ, McCarthy M, Ribeiro Neto ML, Hachamovitch R, Pearson K, et al. (2019) Infliximab for Refractory Cardiac Sarcoidosis. Am J Cardiol 124: 1630 1635. Link: https://bit.ly/3dwr32b

33. Bakker ALM, Mathijssen H, Azzahhafi J, Swaans MJ, Veltkamp M, et al. (2021) Effectiveness and safety of infliximab in cardiac Sarcoidosis. Int J Cardiol 330 : 179-185. Link: https://bit.ly/3GqNLFu
34. Gilotra NA, Wand AL, Pillarisetty A, Devraj M, Pavlovic N, et al. (2021) Clinical and Imaging Response to Tumor Necrosis Factor Alpha Inhibitors in Treatment of Cardiac Sarcoidosis: A Multicenter Experience. J Card Fail 27: 83-91. Link: https://bit.ly/3y7CmYf

35. Heymans S, Eriksson U, Lehtonen J, Cooper LT Jr. (2016) The Quest for New Approaches in Myocarditis and Inflammatory Cardiomyopathy. J Am Coll Cardiol 68: 2348-2364. Link: https://bit.ly/31HpwDC

36. Lee PI, Cheng G, Alavi A (2017) The role of serial FDG PET for assessing therapeutic response in patients with cardiac sarcoidosis. J Nucl Cardiol 24 19-28. Link: https://bit.ly/3ltAvS5

37. Shelke AB, Aurangabadkar HU, Bradfield JS, Ali Z, Kumar KS, et al. (2017) Seria FDG-PET scans help to identify steroid resistance in cardiac sarcoidosis. Int $\mathrm{J}$ Cardiol 228: 717-722. Link: https://bit.ly/3DF4SBj

38. Ning N, Guo HH, lagaru A, Mittra E, Fowler M, et al. (2019) Serial Cardiac FDGPET for the Diagnosis and Therapeutic Guidance of Patients With Cardiac Sarcoidosis. J Card Fail 25: 307-311. Link: https://bit.ly/3du1rmv

39. Wicks EC, Menezes LJ, Barnes A, Mohiddin SA, Sekhri N, et al. (2018) Diagnostic accuracy and prognostic value of simultaneous hybrid 18F-fluorodeoxyglucose positron emission tomography/magnetic resonance imaging in cardiac sarcoidosis. Eur Heart J Cardiovasc Imaging 19: 757-767. Link: https://bit.ly/3ECZrV5

40. Vita T, Okada DR, Veillet-Chowdhury M, Bravo PE, Mullins E, et al. (2018) Complementary Value of Cardiac Magnetic Resonance Imaging and Positron Emission Tomography/Computed Tomography in the Assessment of Cardiac Sarcoidosis. Circ Cardiovasc Imaging 11: e007030. Link: https://bit.ly/3Dyoo2v

41. Shafee MA, Fukuda K, Wakayama Y, Nakano M, Kondo M, et al. (2012) Delayed enhancement on cardiac magnetic resonance imaging is a poor prognostic factor in patients with cardiac sarcoidosis. J Cardiol 60: 448-453. Link: https://bit.ly/3pG1pgs

42. Greulich S, Gatidis S, Grani C, Blankstein R, Glatthaar A, et al. (2021) Hybrid Cardiac Magnetic Resonance/Fluorodeoxyglucose Positron Emission Tomography to Differentiate Active From Chronic Cardiac Sarcoidosis. JACC Cardiovasc Imaging. Link: https://bit.ly/3lvFVMv

43. Mateyo K, Thomeer M (2017) Sarcoidosis around the Globe. Semin Respir Crit Care Med 38: 393-403. Link: https://bit.ly/3dunWb5

44. Ballul T, Borie R, Crestani B, Daugas E, Descamps V, et al. (2019) Treatment of cardiac sarcoidosis: A comparative study of steroids and steroids plus immunosuppressive drugs. Int J Cardiol 276: 208-211. Link: https://bit.ly/3DFzToV

45. Johns CJ, Michele TM (1999) The clinical management of sarcoidosis. A 50 year experience at the Johns Hopkins Hospital. Medicine (Baltimore) 78: 65 111. Link: https://bit.ly/3Gt3Pq5

46. Baughman RP, Field S, Costabel U, Crystal RG, Culver DA, et al. (2016) Sarcoidosis in America. Analysis Based on Health Care Use. Ann Am Thorac Soc 13: 1244-1252. Link: https://bit.ly/3DzUXNv

47. Hillerdal G, Nou E, Osterman K, Schmekel B (1984) Sarcoidosis: epidemiology and prognosis. A 15-year European study. Am Rev Respir Dis 130: 29-32. Link: https://bit.ly/3oEzlpq

48. Byg KE, Milman N, Hansen S (2003) Sarcoidosis in Denmark 1980-1994. A registry-based incidence study comprising 5536 patients. Sarcoidosis Vasc Diffuse Lung Dis 20: 46-52. Link: https://bit.ly/3pyDwlg

49. Gribbin J, Hubbard RB, Le Jeune I, Smith CJ, West J, et al. (2006) Incidence and mortality of idiopathic pulmonary fibrosis and sarcoidosis in the UK. Thorax 61: 980-985. Link: https://bit.ly/3pYbLt1

50. Lopez-Campos JL, Rodriguez-Becerra E, Neumosur Task G, Registry of Interstitial Lung D (2004) Incidence of interstitial lung diseases in the south

Citation: Lynch III JP, Fishbein MC, Bradfield JS, Belperio JA (2021) Cardiac involvement in sarcoidosis: Evolving concepts in diagnosis and treatment. J Cardiovasc Med Cardiol 8(4): 079-102. DOI: https://dx.doi.org/10.17352/2455-2976.000175 
of Spain 1998-2000: the RENIA study. Eur J Epidemiol 19: 155-161. Link: https://bit.ly/3oAW8rD

51. Mise K, Jurcev-Savicevic A, Goic-Barisic I, Kozul K, Gudelj I (2011) Sarcoidosis and tuberculosis in South Croatia: are there epidemiological similarities or not? Public Health 125: 734-737. Link: https://bit.ly/3IKiQWH

52. Yigla M, Badarna-Abu-Ria N, Tov N, Ravell-Weiller D, Rubin AH (2002) Sarcoidosis in northern Israel; clinical characteristics of 120 patients. Sarcoidosis Vasc Diffuse Lung Dis 19: 220-226. Link: https://bit.ly/3lvPsDf

53. Kim DS (2001) Sarcoidosis in Korea: report of the Second Nationwide Survey. Sarcoidosis Vasc Diffuse Lung Dis 18: 176-180. Link: https://bit.ly/3luhuiF

54. Anantham D, Ong SJ, Chuah KL, Fook-Chong S, Hsu A, et al. (2007) Sarcoidosis in Singapore: epidemiology, clinical presentation and ethnic differences. Respirology 12: 355-360. Link: https://bit.ly/3IJ8uGu

55. Morimoto T, Azuma A, Abe S, Usuki J, Kudoh S, et al. (2008) Epidemiology of sarcoidosis in Japan. Eur Respir J 31: 372-379. Link: https://bit.ly/3dwNlkv

56. Yazaki $\mathrm{Y}$, Hongo $\mathrm{M}, \mathrm{Y} \mathrm{H}$, al e (1994) Cardiac sarcoidosis in Japan: treatment and prognosis. In: Sekiguchi M, Richardson PJ, etd Prognosis nad Treatment of Cardiomyopathy and Myoarditis Tokyo: Univ of Tokyo Press 341-53.

57. Sekiguchi M, Yazaki Y, Isobe M, Hiroe M (1996) Cardiac sarcoidosis: diagnostic, prognostic, and therapeutic considerations. Cardiovasc Drugs Ther 10: 495-510. Link: https://bit.ly/3lwclRv

58. Iwai K, Sekiguti M, Hosoda Y, DeRemee RA, Tazelaar HD, et al. (1994) Racial difference in cardiac sarcoidosis incidence observed at autopsy. Sarcoidosis 11: 26-31. Link: https://bit.ly/3y7jlzF

59. Tachibana T, Ohmori F, Ueda E (1986) Clinical study on cardiac sarcoidosis Ann N Y Acad Sci 465: 530-542. Link: https://bit.ly/3Gn1NYu

60. Gideon NM, Mannino DM (1996) Sarcoidosis mortality in the United States 1979-1991: an analysis of multiple-cause mortality data. Am J Med 100: 423427. Link: https://bit.ly/3pFKDi3

61. Fleming HA (1974) Sarcoid heart disease. Br Heart J 36: 54-68. Link: https://bit.ly/3GwflBd

62. Sharma OP, Maheshwari A, Thaker K (1993) Myocardial sarcoidosis. Chest 103: 253-258. Link: https://bit.ly/31E61MA

63. Longcope WT, Freiman DG (1952) A study of sarcoidosis; based on combined investigation of 160 cases including 30 autopsies from The Johns Hopkins Hospital and Massachusetts General Hospital. Medicine (Baltimore) 31: 1-132. Link: https://bit.ly/31E63nG

64. Iannuzzi MC (2007) Genetics of sarcoidosis. Semin Respir Crit Care Med 28: 15-21. Link: https://bit.ly/3Dx4K76

65. Meyer T, Lauschke J, Ruppert V, Richter A, Pankuweit S, et al. (2008) Isolated cardiac sarcoidosis associated with the expression of a splice variant coding for a truncated BTNL2 protein. Cardiology 109: 117-121. Link: https://bit.ly/3y8CTc9

66. Grunewald J (2010) Review: role of genetics in susceptibility and outcome of sarcoidosis. Semin Respir Crit Care Med 31: 380-389. Link: https://bit.ly/3GIAdp1

67. Lagana SM, Parwani AV, Nichols LC (2010) Cardiac sarcoidosis: a pathology-focused review. Arch Pathol Lab Med 134: 1039-1046. Link: https://bit.ly/3074Q7G

68. Yazaki Y, Isobe M, Hiramitsu S, Morimoto S, Hiroe M, et al. (1998) Comparison of clinical features and prognosis of cardiac sarcoidosis and idiopathic dilated cardiomyopathy. Am J Cardiol 82: 537-540. Link: https://bit.ly/3EFcZzm

69. Shammas RL, Movahed A (1993) Sarcoidosis of the heart. Clin Cardiol 16: 462 472. Link: https://bit.ly/307PGPA
70. Ishida M, Niwano S, Fujiyoshi K, Ishida K, Ako J, et al. (2021) A case with recovery from high degree atrioventricular-block with steroid therapy in cardiac sarcoidosis with $\mathrm{AH}$ block: a possible new sign of responder? J Cardiol Cases 23: 90-93. Link: https://bit.ly/3GvvvKP

71. Kim JS, Judson MA, Donnino R, Gold M, Cooper LT Jr, et al. (2009) Cardiac sarcoidosis. Am Heart J 157: 9-21. Link: https://bit.ly/3pF4o9F

72. Aizer A, Stern EH, Gomes JA, Teirstein AS, Eckart RE, et al. (2005) Usefulness of programmed ventricular stimulation in predicting future arrhythmic events in patients with cardiac sarcoidosis. Am J Cardiol 96: 276-282. Link: https://bit.ly/3DEwVRE

73. Thachil A, Christopher J, Sastry BK, Reddy KN, Tourani VK, et al. (2011) Monomorphic ventricular tachycardia and mediastinal adenopathy due to granulomatous infiltration in patients with preserved ventricular function. $J$ Am Coll Cardiol 58: 48-55. Link: https://bit.ly/3y6HufO

74. Nery PB, Beanlands RS, Nair GM, Green M, Yang J, et al. (2014) Atrioventricula block as the initial manifestation of cardiac sarcoidosis in middle-aged adults. J Cardiovasc Electrophysiol 25: 875-881. Link: https://bit.ly/3ETcFgF

75. Fleming H (1994) Cardiac sarcoidosis. In: James DG, ed. Sarcoidosis and other granulomatous disorders. New York: Marcel Dekker 323-334.

76. Viles-Gonzalez JF, Pastori L, Fischer A, Wisnivesky JP, Goldman MG, et al (2013) Supraventricular arrhythmias in patients with cardiac sarcoidosis prevalence, predictors, and clinical implications. Chest 143: 1085-1090. Link: https://bit.ly/3rP1Rfz

77. Zipse MM, Sauer WH (2013) Electrophysiologic manifestations of cardiac sarcoidosis. Curr Opin Pulm Med 19: 485-492. Link: https://bit.ly/30754M4

78. Kosuge $H$, Noda M, Kakuta $T$, Kishi $Y$, Isobe M, et al. (2001) Left ventricular apical aneurysm in cardiac sarcoidosis. Jpn Heart J 42: 265-269. Link: https://bit.ly/3oBpoi0

79. Marks A, Anderson MH, Harrison NK (2004) Ventricular aneurysm secondary to sarcoid disease. Heart 90: 694. Link: https://bit.ly/3oDryxl

80. Haraki T, Ueda K, Shintani H, Hayashi T, Taki J, et al. (2002) Spontaneous development of left ventricular aneurysm in a patient with untreated cardiac sarcoidosis. Circ J 66 :519-521. Link: https://bit.ly/3DAYBXI

81. Pedrotti P, Ammirati E, Bonacina E, Roghi A (2015) Ventricular aneurysms in cardiac sarcoidosis: From physiopathology to surgical treatment through a clinical case presenting with ventricular arrhythmias. Int J Cardiol 186: 294 296. Link: https://bit.ly/3lxOgPE

82. Miyazawa K, Yoshikawa T, Takamisawa I, Mahara $\mathrm{K}$, Inoue $\mathrm{K}$, et al (2014) Presence of ventricular aneurysm predicts poor clinical outcomes in patients with cardiac sarcoidosis. Int J Cardiol 177: 720-722. Link: https://bit.ly/3Dx5F7u

83. Desai MY, Fallert MA (2003) Rapidly progressing congestive heart failure due to cardiac sarcoidosis involving papillary muscles: a case report and brief review of the literature. Cardiol Rev 11: 163-168. Link: https://bit.ly/3rT44Xo

84. Raftery EB, Oakley CM, Goodwin JF (1966) Acute subvalvar mitral incompetence. Lancet 2: 360-365. Link: https://bit.ly/307Qhki

85. Israel RH, Poe RH (1994) Massive pericardial effusion in sarcoidosis Respiration 61:176-180. Link: https://bit.ly/3y8XixU

86. Kinney E, Murthy R, Ascunce G, Donohoe R, Zelis R (1979) Pericardial effusions in sarcoidosis. Chest 76: 476-478. Link: https://bit.ly/3dBGqGu

87. Verkleeren JL, Glover MU, Bloor C, Joswig BC (1983) Cardiac tamponade secondary to sarcoidosis. Am Heart J 106: 601-603. Link: https://bit.ly/3GrZinJ

88. Angomachalelis N, Hourzamanis A, Salem N, Vakalis D, Serasli E, et al. (1994) Pericardial effusion concomitant with specific heart muscle

Citation: Lynch III JP, Fishbein MC, Bradfield JS, Belperio JA (2021) Cardiac involvement in sarcoidosis: Evolving concepts in diagnosis and treatment. J Cardiovasc Med Cardiol 8(4): 079-102. DOI: https://dx.doi.org/10.17352/2455-2976.000175 
disease in systemic sarcoidosis. Postgrad Med J 70: S8-S12. Link: https://bit.ly/3DJRCvC

89. Garrett J, O'Neill H, Blake S (1984) Constrictive pericarditis associated with sarcoidosis. Am Heart J 107: 394. Link: https://bit.ly/3INgM6h

90. Barton JH, Tavora F, Farb A, Li L, Burke AP (2010) Unusual cardiovascular manifestations of sarcoidosis, a report of three cases: coronary artery aneurysm with myocardial infarction, symptomatic mitral valvular disease, and sudden death from ruptured splenic artery. Cardiovasc Pathol 19: e119-e123. Link: https://bit.ly/3oBRaLp

91. Wait JL, Movahed A (1989) Anginal chest pain in sarcoidosis. Thorax 44: 391 395. Link: https://bit.ly/3rQT10W

92. Lam CS, Tolep KA, Metke MP, Glockner J, Cooper LT Jr (2009) Coronary sarcoidosis presenting as acute coronary syndrome. Clin Cardiol 32: E68-E71. Link: https://bit.ly/3DEurTI

93. Ward EV, Nazari J, Edelman RR (2012) Coronary artery vasculitis as a presentation of cardiac sarcoidosis. Circulation 125: e344-e346. Link: https://bit.ly/3GruhAl

94. Giudicatti L, Marangou J, Nolan D, Dembo L, Baumwol J, et al. (2020) The Utility of Whole Body (18)F-FDG PET-CT in Diagnosing Isolated Cardiac Sarcoidosis: The Western Australian Cardiac Sarcoid Study. Heart Lung Circ 29: e1-e6. Link: https://bit.ly/3oEnFc4

95. Belperio JA, Shaikh F, Abtin F, Fishbein MC, Saggar R ,et al. (2021) Extrapulmonary sarcoidosis with a focus on cardiac, nervous system, and ocular involvement. EClinicalMedicine 37: 100966. Link: https://bit.ly/3oEW22x

96. Ohara K, Okubo A, Kamata K, Sasaki H, Kobayashi J, et al. (1993) Transbronchia lung biopsy in the diagnosis of suspected ocular sarcoidosis. Arch Ophthalmol 111: 642-644. Link: https://bit.ly/3EHClg6

97. Chauvelot P, Skanjeti A, Jamilloux Y, de Parisot A, Broussolle C, et al. (2019) (18)F-fluorodeoxyglucose positron emission tomography is useful for the diagnosis of intraocular sarcoidosis in patients with a normal CT scan. $\mathrm{Br} \mathrm{J}$ Ophthalmol 103: 1650-1655. Link: https://bit.ly/3dvvGcS

98. Kandolin R, Lehtonen J, Graner M, Schildt J, Salmenkivi K, et al. (2011) Diagnosing isolated cardiac sarcoidosis. J Intern Med 270: 461-468. Link: https://bit.ly/3y8rtou

99. Ekstrom K, Lehtonen J, Nordenswan HK, Mäyränpää MI, Räisänen-Sokolowsk A, et al. (2019) Sudden death in cardiac sarcoidosis: an analysis of nationwide clinical and cause-of-death registries. Eur Heart J 40: 3121-3128. Link: https://bit.ly/3y8x8eu

100. Hiraga H, Iwai K, Hiroe M, Omori F, Sekiguchi M, et al. (1993) Guidelines for diagnosis of cardiac sarcoidosis: study report on diffuse pulmonary diseases. In: Tokyo: The Japanese Ministry of Health and Ministry 23-24.

101. Judson MA, Baughman RP, Teirstein AS, Terrin ML, Yeager H (1999) Defining organ involvement in sarcoidosis: the ACCESS proposed instrument. ACCESS Research Group. A Case Control Etiologic Study of Sarcoidosis. Sarcoidosis Vasc Diffuse Lung Dis 16: 75-86. Link: https://bit.ly/3pFnYIY

102. Birnie DH, Sauer WH, Bogun F, Cooper JM, Culver DA, et al. (2014) HRS expert consensus statement on the diagnosis and management of arrhythmias associated with cardiac sarcoidosis. Heart Rhythm 11: 13051323. Link: https://bit.ly/3IKJV20

103. Okayama K, Kurata C, Tawarahara K, Wakabayashi Y, Chida K, et al (1995) Diagnostic and prognostic value of myocardial scintigraphy with thallium-201 and gallium-67 in cardiac sarcoidosis. Chest 107: 330-334. Link: https://bit.ly/3oAe7yB

104. White JA, Rajchl M, Butler J, Thompson RT, Prato FS, et al. (2013) Active cardiac sarcoidosis: first clinical experience of simultaneous positron emission tomography--magnetic resonance imaging for the diagnosis of cardiac disease. Circulation 127: e639- e641. Link: https://bit.ly/33cBUwj

105. Youssef G, Leung E, Mylonas I, Nery P, Williams K, et al. (2012) The use of 18F-FDG PET in the diagnosis of cardiac sarcoidosis: a systematic review and metaanalysis including the Ontario experience. J Nucl Med 53: 241248. Link: https://bit.ly/3rMZ7iH

106. Akbar JJ, Meyer CA, Shipley RT, Vagal AS (2008) Cardiopulmonary imaging in sarcoidosis. Clin Chest Med 29: 429-443. Link: https://bit.ly/3oxihav

107. Statement on sarcoidosis. Joint Statement of the American Thoracic Society (ATS) (1999) The European Respiratory Society (ERS) and the World Association of Sarcoidosis and Other Granulomatous Disorders (WASOG) adopted by the ATS Board of Directors and by the ERS Executive Committee, February 1999. Am J Respir Crit Care Med 160: 736-755. Link: https://bit.ly/3pFnBrA

108. Gibbons WJ, Levy RD, Nava S, Malcolm I, Marin JM, et al. (1991) Subclinical cardiac dysfunction in sarcoidosis. Chest 100: 44-50. Link: https://bit.ly/3Dx4EfD

109. Thunell M, Bjerle $P$, Stjernberg N (1983) ECG abnormalities in patients with sarcoidosis. Acta Med Scand 213: 115-118. Link: https://bit.ly/3Iw1zjK

110. Darlington P, Gabrielsen A, Sorensson P, Cederlund K, Eklund A, et al. (2014) Cardiac involvement in Caucasian patients with pulmonary sarcoidosis. Respir Res 15: 15. Link: https://bit.ly/3dw9rU1

111. Martusewicz-Boros MM, Boros PW, Wiatr E, Zych J, Piotrowska-Kownacka D, et al. (2016) Prevalence of cardiac sarcoidosis in white population: a case-control study: Proposal for a novel risk index based on commonly available tests. Medicine (Baltimore) 95: e4518. Link: https://bit.ly/30bil0U

112. Winters SL, Cohen M, Greenberg S, Stein B, Curwin J, et al. (1991) Sustained ventricular tachycardia associated with sarcoidosis: assessment of the underlying cardiac anatomy and the prospective utility of programmed ventricular stimulation, drug therapy and an implantable antitachycardia device. J Am Coll Cardiol 18: 937-943. Link: https://bit.ly/3EzTIVu

113. Angomachalelis N, Hourzamanis A, Vamvalis C, Gavrielides A (1992) Doppler echocardiographic evaluation of left ventricular diastolic function in patients with systemic sarcoidosis. Postgrad Med J 68: S52- S56. Link: https://bit.ly/3y5eAMg

114. Nagano N, Nagai T, Sugano $Y$, Morita $Y$, Asaumi $Y$, et al. (2015) Association Between Basal Thinning of Interventricular Septum and Adverse Long-Term Clinical Outcomes in Patients With Cardiac Sarcoidosis. Circ J 79: 16011608. Link: https://bit.ly/3luZqoi

115. Di Stefano C, Bruno G, Arciniegas Calle MC, Acharya GA, Fussne LM, et al. (2020) Diagnostic and predictive value of speckle tracking echocardiography in cardiac sarcoidosis. BMC Cardiovasc Disord 20: 21. Link: https://bit.ly/3Gmli3x

116. Orii M, Hirata K, Tanimoto $T$, Shiono $Y$, Shimamura $K$, et al. (2015) Myocardial Damage Detected by Two-Dimensional Speckle-Tracking Echocardiography in Patients with Extracardiac Sarcoidosis: Comparison with Magnetic Resonance Imaging. J Am Soc Echocardiogr 28: 683-691. Link: https://bit.ly/3dxCvuk

117. Schouver ED, Moceri P, Doyen D, Tieulie N, Queyrel V, et al. (2017) Early detection of cardiac involvement in sarcoidosis with 2-dimensional speckle-tracking echocardiography. Int J Cardiol 227: 711-716. Link: https://bit.ly/3GpeYYT

118. Tigen K, Sunbul M, Karaahmet T, Tasar O, Dundar C, et al. (2015) Early Detection of Bi-ventricular and Atrial Mechanical Dysfunction Using Two-Dimensional Speckle Tracking Echocardiography in Patients with Sarcoidosis. Lung 193: 669-675. Link: https://bit.ly/3Iz8KHN

119. Tawarahara K, Kurata C, Okayama K, Kobayashi A, Yamazaki N (1992)

Citation: Lynch III JP, Fishbein MC, Bradfield JS, Belperio JA (2021) Cardiac involvement in sarcoidosis: Evolving concepts in diagnosis and treatment. J Cardiovasc Med Cardiol 8(4): 079-102. DOI: https://dx.doi.org/10.17352/2455-2976.000175 
Thallium-201 and gallium 67 single photon emission computed tomographic imaging in cardiac sarcoidosis. Am Heart J 124: 1383-1384. Link: https://bit.ly/3ye48SU

120. Tellier P, Paycha F, Antony I, Nitenberg A, Valeyre D, et al. (1988) Reversibility by dipyridamole of thallium-201 myocardial scan defects in patients with sarcoidosis. Am J Med 85: 189-193. Link: https://bit.ly/3y4sqyD

121. Yamamoto N, Gotoh K, Yagi Y (1993) Thallium-201 myocardial SPECT findings at rest in sarcoidosis. Ann Nucl Med 7: 97-103. Link: https://bit.ly/3y5J3K5

122. Mana J (1997) Nuclear imaging. 67Gallium, 201thallium, 18F-labeled fluoro-2-deoxy-D-glucose positron emission tomography. Clin Chest Med 18: 799-811. Link: https://bit.ly/3pH1L7j

123. Tellier P, Valeyre D, Nitenberg A, Foult JM, Bedig G, et al. (1985) Cardiac sarcoidosis: reversion of myocardial perfusion abnormalities by dipyridamole. Eur J Nucl Med 11: 201-204. Link: https://bit.ly/3DBDJPZ

124. Yang Y, Safka K, Graham JJ, Roifman I, Zia Ml, et al. (2013) Correlation of late gadolinium enhancement MRI and quantitative T2 measurement in cardiac sarcoidosis. J Magn Reson Imaging 39: 609-616. Link: https://bit.ly/3IM03Ae

125. Dweck MR, Abgral R, Trivieri MG, Robson PM, Karakatsanis N, et al. (2018) Hybrid Magnetic Resonance Imaging and Positron Emission Tomography With Fluorodeoxyglucose to Diagnose Active Cardiac Sarcoidosis. JACC Cardiovasc Imaging 11: 94-107. Link: https://bit.ly/3Gm8E4s

126. Mostard RL, Verschakelen JA, van Kroonenburgh MJ, Nelemans PJ, Wijnen PA, et al. (2013) Severity of pulmonary involvement and (18) F-FDG PET activity in sarcoidosis. Respir Med 107: 439-447. Link: https://bit.ly/3IHE7Gf

127. Teirstein AS, Machac J, Almeida O, Lu P, Padilla ML, et al. (2007) Results of 188 whole-body fluorodeoxyglucose positron emission tomography scans in 137 patients with sarcoidosis. Chest 132: 1949-1953. Link: https://bit.ly/334tZkt

128. Sobic-Saranovic D, Artiko V, Obradovic V (2013) FDG PET imaging in sarcoidosis. Semin Nucl Med 43: 404-411. Link: https://bit.ly/31MS7I0

129. Mostard RL, Voo S, van Kroonenburgh MJ, et al. (2011) Inflammatory activity assessment by F18 FDG-PET/CT in persistent symptomatic sarcoidosis. Respir Med 105: 1917-1924. Link: https://bit.ly/3ovoGmt

130. Mc Ardle BA, Leung E, Ohira H, Cocker MS, DeKemp RA, et al. (2013) The role of $F(18)$-fluorodeoxyglucose positron emission tomography in guiding diagnosis and management in patients with known or suspected cardiac sarcoidosis. J Nucl Cardiol 20: 297-306. Link: https://bit.ly/3EAbDWs

131. Nishiyama $Y$, Yamamoto $Y$, Fukunaga $K$, Takinami H, Iwado $Y$, et al. (2006) Comparative evaluation of 18F-FDG PET and 67Ga scintigraphy in patients with sarcoidosis. J Nucl Med 47: 1571-1576. Link: https://bit.ly/3ls7dmW

132. Okumura W, Iwasaki T, Toyama T, Iso T, Arai M, et al. (2004) Usefulness of fasting 18F-FDG PET in identification of cardiac sarcoidosis. J Nucl Med 45: 1989-1998. Link: https://bit.ly/3INHAmK

133. Yamagishi H, Shirai N, Takagi M, Yoshiyama M, Akioka K, et al. (2003) Identification of cardiac sarcoidosis with (13)N-NH(3)/(18)F-FDG PET. J Nucl Med 44: 1030-1036. Link: https://bit.ly/306IldD

134. Blankstein R, Osborne M, Naya M, Waller A, Kim CK, et al. (2014) Cardiac positron emission tomography enhances prognostic assessments of patients with suspected cardiac sarcoidosis. J Am Coll Cardiol 63: 329-336. Link: https://bit.ly/3ECRHCv

135. Osborne MT, Hulten EA, Murthy VL, Skali H, Taqueti VR, et al. (2017) Patien preparation for cardiac fluorine-18 fluorodeoxyglucose positron emission tomography imaging of inflammation. J Nucl Cardiol 24: 86-99. Link: https://bit.ly/3pFTEYi
136. Schatka I, Bengel FM (2014) Advanced Imaging of Cardiac Sarcoidosis. J Nucl Med 55: 99-106. Link: https://bit.ly/3rNb1cG

137. Ishimaru S, Tsujino I, Takei T, Tsukamoto E, Sakaue S, et al. (2005) Focal uptake on 18F-fluoro-2-deoxyglucose positron emission tomography images indicates cardiac involvement of sarcoidosis. Eur Heart J 26: 15381543. Link: https://bit.ly/3IG6Dbx

138. Braun JJ, Kessler R, Constantinesco A, Imperiale A (2008) 18F-FDG PET/CT in sarcoidosis management: review and report of 20 cases. Eur $\mathrm{J}$ Nucl Med Mol Imaging 35: 1537-1543. Link: https://bit.ly/3ovWwYC

139. Ohira H, Birnie DH, Pena E, Bernick J, Mc Ardle B, et al. (2016) Comparison of (18)F-fluorodeoxyglucose positron emission tomography (FDG PET) and cardiac magnetic resonance (CMR) in corticosteroid-naive patients with conduction system disease due to cardiac sarcoidosis. Eur J Nucl Med Mol Imaging 43: 259-269. Link: https://bit.ly/31FNaka

140. Bartlett ML, Bacharach SL, Voipio-Pulkki LM, Dilsizian V (1995) Artifactual inhomogeneities in myocardial PET and SPECT scans in normal subjects. $J$ Nucl Med 36: 188-195. Link: https://bit.ly/3dxMUq4

141. Ohira H, Tsujino I, Ishimaru S, Oyama N, Takei T, et al. (2008) Myocardia imaging with $18 \mathrm{~F}$-fluoro-2-deoxyglucose positron emission tomography and magnetic resonance imaging in sarcoidosis. Eur $\mathrm{J}$ Nucl Med Mol Imaging 35: 933-941. Link: https://bit.ly/3EFRyhx

142. Galati G, Leone O, Rapezzi C (2014) The difficult diagnosis of isolated cardiac sarcoidosis: usefulness of an integrated MRI and PET approach. Heart 100: 89-90. Link: https://bit.ly/3dvXuhm

143. Ordovas KG, Higgins CB (2011) Delayed contrast enhancement on MR images of myocardium: past, present, future. Radiology 261: 358-374. Link: https://bit.ly/3dw8zyJ

144. Ohira H, Tsujino I, Yoshinaga K (2011) ${ }^{18}$ F-Fluoro-2-deoxyglucose positron emission tomography in cardiac sarcoidosis. Eur J Nucl Med Mol Imaging 38: 1773-1783. Link: https://bit.ly/3DGXISU

145. Vignaux O (2005) Cardiac sarcoidosis: spectrum of MRI features. AJR Am J Roentgenol 184: 249-254. Link: https://bit.ly/3rliCZX

146. Giesbrandt KJ, Bolan CW, Shapiro BP, Edwards WD, Mergo PJ (2013) Diffuse diseases of the myocardium: MRI-pathologic review of cardiomyopathies with dilatation. AJR Am J Roentgenol 200: W274-282. Link: https://bit.ly/3GnzxFd

147. Smedema JP, Snoep G, van Kroonenburgh MP, van Geuns RJ, Dassen WR, et al. (2005) Evaluation of the accuracy of gadolinium-enhanced cardiovascular magnetic resonance in the diagnosis of cardiac sarcoidosis. J Am Coll Cardiol 45:1683-1690. Link: https://bit.ly/3dyirbb

148. Smedema JP, Ainslie G, Crijns H (2020) Review: Contrast-enhanced magnetic resonance in the diagnosis and management of cardiac sarcoidosis. Prog Cardiovasc Dis 63: 271-307. Link: https://bit.ly/3m6zPJ5

149. Chandra M, Silverman ME, Oshinski J, Pettigrew R (1996) Diagnosis of cardiac sarcoidosis aided by MRI. Chest 110: 562-565. Link https://bit.ly/3y7k21h

150. Shimada T, Shimada K, Sakane T, Ochiai K, Tsukihashi H, et al. (2001) Diagnosis of cardiac sarcoidosis and evaluation of the effects of steroid therapy by gadolinium-DTPA-enhanced magnetic resonance imaging. Am J Med 110: 520-527. Link: https://bit.ly/3s1B53Z

151. Matsuki M, Matsuo M (2000) MR findings of myocardial sarcoidosis. Clin Radiol 55: 323-325. Link: https://bit.ly/3dvWVnK

152. Vignaux O, Dhote R, Duboc D, Blanche P, Devaux JY, et al. (2002) Detection of myocardial involvement in patients with sarcoidosis applying T2weighted, contrast-enhanced, and cine magnetic resonance imaging: initial results of a prospective study. J Comput Assist Tomogr 26: 762-767. Link https://bit.ly/3EBO9IH

Citation: Lynch III JP, Fishbein MC, Bradfield JS, Belperio JA (2021) Cardiac involvement in sarcoidosis: Evolving concepts in diagnosis and treatment. J Cardiovasc Med Cardiol 8(4): 079-102. DOI: https://dx.doi.org/10.17352/2455-2976.000175 
153. Ichinose A, Otani H, Oikawa M, Takase K, Saito H, et al. (2008) MRI of cardiac sarcoidosis: basal and subepicardial localization of myocardial lesions and their effect on left ventricular function. AJR Am J Roentgenol 191: 862-869. Link: https://bit.ly/3IKljWO

154. Matoh F, Satoh H, Shiraki K, Odagiri K, Saitoh T, et al. (2008) The usefulness of delayed enhancement magnetic resonance imaging for diagnosis and evaluation of cardiac function in patients with cardiac sarcoidosis. J Cardiol 51: 179-188. Link: https://bit.ly/3DuDRkh

155. Watanabe E, Kimura F, Nakajima T, Hiroe M, Kasai Y, et al. (2013) Late gadolinium enhancement in cardiac sarcoidosis: characteristic magnetic resonance findings and relationship with left ventricular function. J Thorac Imaging 28: 60-66. Link: https://bit.ly/3067jzn

156. Yoshida A, Ishibashi-Ueda H, Yamada N, Kanzaki H, Hasegawa T, et al (2013) Direct comparison of the diagnostic capability of cardiac magnetic resonance and endomyocardial biopsy in patients with heart failure. Eur $\mathrm{J}$ Heart Fail 15: 166-175. Link: https://bit.ly/31yjGFc

157. Patel AR, Klein MR, Chandra S, Spencer KT, Decara JM, et al. (2011) Myocardial damage in patients with sarcoidosis and preserved left ventricular systolic function: an observational study. Eur $\mathrm{J}$ Heart Fail 13 1231-1237. Link: https://bit.ly/3GkfnMe

158. Cheong BY, Muthupillai R, Nemeth M, Lambert B, Dees D, et al. (2009) The utility of delayed-enhancement magnetic resonance imaging for identifying nonischemic myocardial fibrosis in asymptomatic patients with biopsyproven systemic sarcoidosis. Sarcoidosis. Vasc Diffuse Lung Dis 26: 39-46. Link: https://bit.ly/3dMcAzr

159. Ishibashi K, Takeda M, Yamahara Y (2013) Clinical utility of a magneti resonance-conditional pacemaker in a patient with cardiac sarcoidosis. Intern Med 52: 1341-1345. Link: https://bit.ly/3DEWeTn

160. Hulten E, Agarwal V, Cahill M, Cole G, Vita T, et al. (2016) Presence of Late Gadolinium Enhancement by Cardiac Magnetic Resonance Among Patients With Suspected Cardiac Sarcoidosis Is Associated With Adverse Cardiovascular Prognosis: A Systematic Review and Meta-Analysis. Circ Cardiovasc Imaging 9: e005001. Link: https://bit.ly/3dMcA2p

161. Nagai T, Kohsaka S, Okuda S, Anzai T, Asano K, et al. (2014) Incidence and prognostic significance of myocardial late gadolinium enhancement in patients with sarcoidosis without cardiac manifestation. Chest 146: 1064 1072. Link: https://bit.ly/31EkUOH

162. Ekstrom K, Lehtonen J, Hanninen $\mathrm{H}$, Kandolin R, Kivisto S, et al. (2016) Magnetic Resonance Imaging as a Predictor of Survival Free of LifeThreatening Arrhythmias and Transplantation in Cardiac Sarcoidosis. J Am Heart Assoc 5: e003040. Link: https://bit.ly/3GqPWJ6

163. Ekstrom K, Raisanen-Sokolowski A, Lehtonen J, Nordenswan HK, Mayranpaa MI, et al. (2020) Idiopathic giant cell myocarditis or cardiac sarcoidosis? A retrospective audit of a nationwide case series. ESC Heart Fail 7: 1362-1370. Link: https://bit.ly/3EzRLTy

164. Franke KB, Marshall $H$, Kennewell P, Pham HD, Tully PJ, et al. (2021) Risk and predictors of sudden death in cardiac sarcoidosis: A systematic review and meta-analysis. Int J Cardiol 328: 130-140. Link: https://bit.ly/3y3grBn

165. Greulich S, Kitterer D, Latus J, Aguor E, Steubing H, et al. (2016) Comprehensive Cardiovascular Magnetic Resonance Assessment in Patients With Sarcoidosis and Preserved Left Ventricular Ejection Fraction. Circ Cardiovasc Imaging 9: e005022. Link: https://bit.ly/3rLGvj7

166. Crouser ED, Ono C, Tran T, He X, Raman SV (2014) Improved detection of cardiac sarcoidosis using magnetic resonance with myocardial T2 mapping. Am J Respir Crit Care Med 189: 109-112. Link: https://bit.ly/3y9CzKf

167. Puntmann VO, Isted A, Hinojar R, Foote L, Carr-White G, et al. (2017) T1 and T2 Mapping in Recognition of Early Cardiac Involvement in Systemic Sarcoidosis. Radiology 285: 63-72. Link: https://bit.ly/3ol1phv
168. Wilkoff BL, Bello D, Taborsky M, Vymazal J, Kanal E, et al. (2011) Magnetic resonance imaging in patients with a pacemaker system designed for the magnetic resonance environment. Heart Rhythm 8: 65-73. Link: https://bit.ly/33bip7n

169. Ishikawa T, Kondoh H, Nakagawa S, Koiwaya Y, Tanaka K (1984) Steroid therapy in cardiac sarcoidosis. Increased left ventricular contractility concomitant with electrocardiographic improvement after prednisolone. Chest 85: 445-447. Link: https://bit.ly/3DzH02b

170. Lorell B, Alderman EL, Mason JW (1978) Cardiac sarcoidosis. Diagnosis with endomyocardial biopsy and treatment with corticosteroids. Am J Cardiol 42: 143-146. Link: https://bit.ly/3lux2mq

171. Ratner SJ, Fenoglio JJ, Ursell PC (1986) Utility of endomyocardia biopsy in the diagnosis of cardiac sarcoidosis. Chest 90: 528-533. Link: https://bit.ly/31HhfQ4

172. Sekiguchi M, Numao Y, Imai M, Furuie T, Mikami R (1980) Clinical and histopathological profile of sarcoidosis of the heart and acute idiopathic myocarditis. Jpn Circ J 44: 249-263. Link: https://bit.ly/3355fZr

173. Uemura A, Morimoto S, Hiramitsu S, Kato Y, Ito T, et al. (1999) Histologic diagnostic rate of cardiac sarcoidosis: evaluation of endomyocardial biopsies. Am Heart J 138: 299-302. Link: https://bit.ly/31EkXtR

174. Liang JJ, Hebl VB, DeSimone CV, Madhavan M, Nanda S, et al. (2014) Electrogram guidance: a method to increase the precision and diagnostic yield of endomyocardial biopsy for suspected cardiac sarcoidosis and myocarditis. JACC Heart Fail 2: 466-473. Link: https://bit.ly/3rQhCmu

175. Frustaci A, Russo MA, Chimenti C (2013) Diagnostic contribution of left ventricular endomyocardial biopsy in patients with clinical phenotype of hypertrophic cardiomyopathy. Hum Pathol 44: 133-141. Link: https://bit.ly/3rLGmfz

176. Felker GM, Hu W, Hare JM, Hruban RH, Baughman KL, et al. (1999) The spectrum of dilated cardiomyopathy. The Johns Hopkins experience with 1,278 patients. Medicine (Baltimore) 78: 270-283. Link: https://bit.ly/3INc6x7

177. Veinot JP (2002) Diagnostic endomyocardial biopsy pathology: secondary myocardial diseases and other clinical indications - a review. Can J Cardiol 18: $287-296$

178. Dechering DG, Kochhauser S, Wasmer K, Zellerhoff S, Pott C, et al. (2013) Electrophysiological characteristics of ventricular tachyarrhythmias in cardiac sarcoidosis versus arrhythmogenic right ventricular cardiomyopathy. Heart Rhythm 10: 158-164. Link: https://bit.ly/31vSE1f

179. Quarta G, Husain SI, Flett AS, Sado DM, Chao CY, et al. (2013) Arrhythmogenic right ventricular cardiomyopathy mimics: role of cardiovascular magnetic resonance. J Cardiovasc Magn Reson 15: 16. Link: https://bit.ly/3rMDpvi

180. Yoshizawa S, Kato TS, Mancini D, Marboe CC (2013) Outcome of patients having heart transplantation for lymphocytic myocarditis. Am J Cardiol 112: 405-410. Link: https://bit.ly/3y2xraU

181. Mavrogeni S, Sfikakis PP, Gialafos E, Bratis K, Karabela G, et al. (2013) Cardiac tissue characterization and the diagnostic value of cardiovascula magnetic resonance in systemic connective tissue diseases. Arthritis Care Res (Hoboken) 66: 104-112. Link: https://bit.ly/3rS3pFT

182. Miszalski-Jamka T, Szczeklik W, Sokolowska B, Karwat K, Belzak K, et al (2013) Standard and feature tracking magnetic resonance evidence of myocardial involvement in Churg-Strauss syndrome and granulomatosis with polyangiitis (Wegener's) in patients with normal electrocardiograms and transthoracic echocardiography. Int J Cardiovasc Imaging 29: 843-853. Link: https://bit.ly/3ye2020

183. Nguyen $Y$, Guillevin $L$ (2018) Eosinophilic Granulomatosis with Polyangiitis (Churg-Strauss). Semin Respir Crit Care Med 39: 471-481. Link: https://bit.ly/3GnyPb1

Citation: Lynch III JP, Fishbein MC, Bradfield JS, Belperio JA (2021) Cardiac involvement in sarcoidosis: Evolving concepts in diagnosis and treatment. J Cardiovasc Med Cardiol 8(4): 079-102. DOI: https://dx.doi.org/10.17352/2455-2976.000175 
184. Kang EJ, Kim SM, Choe YH, Lee GY, Lee KN, et al. (2013) Takayasu Arteritis: Assessment of Coronary Arterial Abnormalities with 128-Section DualSource CT Angiography of the Coronary Arteries and Aorta. Radiology 270 : 74-81. Link: https://bit.ly/3y3Nh50

185. Mohty D, Damy T, Cosnay P, Echahidi N, Casset-Senon D, et al. (2013) Cardiac amyloidosis: Updates in diagnosis and management. Arch Cardiovasc Dis 106: 528-540. Link: https://bit.ly/3ILORW3

186. Marques N, Gan VC, Leo YS (2013) Dengue myocarditis in Singapore: two case reports. Infection 41: 709-714. Link: https://bit.ly/3oAbVXT

187. Nunes MC, Dones W, Morillo CA, Encina JJ, Ribeiro AL (2013) Council on Chagas Disease of the Interamerican Society of C. Chagas disease: an overview of clinical and epidemiological aspects. J Am Coll Cardiol 62: 767776. Link: https://bit.ly/3pGfRWr

188. Priori SG, Gasparini M, Napolitano C, Della Bella P, Ottonelli AG, et al (2012) Risk stratification in Brugada syndrome: results of the PRELUDE (PRogrammed ELectrical stimUlation preDictive valuE) registry. J Am Coll Cardiol 59: 37-45. Link: https://bit.ly/3EAZyjX

189. Mehta D, Lubitz SA, Frankel Z, Wisnivesky JP, Einstein AJ, et al. (2008) Cardiac involvement in patients with sarcoidosis: diagnostic and prognostic value of outpatient testing. Chest 133: 1426-1435. Link: https://bit.ly/3pFmdos

190. Mehta D, Mori N, Goldbarg SH, Lubitz S, Wisnivesky JP, et al. (2011) Primary prevention of sudden cardiac death in silent cardiac sarcoidosis: role of programmed ventricular stimulation. Circ Arrhythm Electrophysiol 4: 43-48 Link: https://bit.ly/31BljBK

191. Uusimaa P, Ylitalo K, Anttonen O, Kerola T, Virtanen V, et al. (2008) Ventricular tachyarrhythmia as a primary presentation of sarcoidosis. Europace 10: 760-766. Link: https://bit.ly/3Iw5E7G

192. Riezzo I, Ventura F, D'Errico S, Neri M, Turillazzi E, et al. (2009) Arrhythmogenesis and diagnosis of cardiac sarcoidosis. An immunohistochemical study in a sudden cardiac death. Forensic Sci Int 183: e1-5. Link: https://bit.ly/3lpphy9

193. Kato Y, Morimoto S, Uemura A, Hiramitsu S, Ito T, et al. (2003) Efficacy of corticosteroids in sarcoidosis presenting with atrioventricular block. Sarcoidosis Vasc Diffuse Lung Dis 20: 133-137. Link: https://bit.ly/3ILkcGq

194. Shabetai R (2000) Sarcoidosis and the Heart. Curr Treat Options Cardiovasc Med 2: 385-398.

195. Padilla ML (2010) Cardiac Sarcoidosis. In: Sarcoidosis (RP Baughman, Ed) informaUSA, New York, NY 210: 515-551.

196. Mezaki T, Chinushi M, Washizuka T, Furushima H, Chinushi Y, et al. (2001) Discrepancy between inducibility of ventricular tachycardia and activity of cardiac sarcoidosis. Requirement of defibrillator implantation for the inactive stage of cardiac sarcoidosis. Intern Med 40: 731-735. Link: https://bit.ly/3DzKWjm

197. Huang PL, Brooks R, Carpenter C, Garan H (1991) Antiarrhythmic therapy guided by programmed electrical stimulation in cardiac sarcoidosis with ventricular tachycardia. Am Heart J 121: 599-601. Link: https://bit.ly/3dyhEHf

198. Jefic D, Joel B, Good E, Morady F, Rosman H, et al. (2009) Role of radiofrequency catheter ablation of ventricular tachycardia in cardiac sarcoidosis: report from a multicenter registry. Heart Rhythm 6: 189-195. Link: https://bit.ly/3INonSq

199. Hiramastu S, Tada H, Naito S, Oshima S, Taniguchi K (2009) Steroid treatment deteriorated ventricular tachycardia in a patient with right ventricle-dominant cardiac sarcoidosis. Int J Cardiol 132: e85- e87. Link: https://bit.ly/31BhRXX

200. Stees CS, Khoo MS, Lowery CM, Sauer WH (2011) Ventricular tachycardia storm successfully treated with immunosuppression and catheter ablation in a patient with cardiac sarcoidosis. J Cardiovasc Electrophysiol 22: 210213. Link: https://bit.ly/3yjxUWt

201. Schuller JL, Zipse M, Crawford T, Bogun F, Beshai J, et al. (2012) Implantable cardioverter defibrillator therapy in patients with cardiac sarcoidosis. $\mathrm{J}$ Cardiovasc Electrophysiol 23: 925-929. Link: https://bit.ly/3pyHOiQ

202. Betensky BP, Tschabrunn CM, Zado ES, Goldberg LR, Marchlinski FE, et al. (2012) Long-term follow-up of patients with cardiac sarcoidosis and implantable cardioverter-defibrillators. Heart Rhythm 9: 884-891. Link: https://bit.ly/31KQGd8

203. Paz HL, McCormick DJ, Kutalek SP, Patchefsky A (1994) The automated implantable cardiac defibrillator. Prophylaxis in cardiac sarcoidosis. Chest 106: 1603-1607. Link: https://bit.ly/3GqMLkp

204. Takada K, Ina Y, Yamamoto M, Satoh T, Morishita M (1994) Prognosis after pacemaker implantation in cardiac sarcoidosis in Japan. Clinical evaluation of corticosteroid therapy. Sarcoidosis 11: 113-117. Link: https://bit.ly/3oAMepZ

205. Chinushi M, Mezaki T, Aoki Y, Nakagawa I, Washizuka Tet al. (2000) Demonstration of transient entrainment in monomorphic sustained ventricular tachycardia associated with cardiac sarcoidosis. Jpn Circ J 64 635-637. Link: https://bit.ly/3Gtw4VO

206. Birnie DH, Sauer WH, Judson MA (2016) Consensus statement on the diagnosis and management of arrhythmias associated with cardiac sarcoidosis. Heart 102: 411-414. Link: https://bit.ly/3pEhZOq

207. Mohsen A, Jimenez A, Hood RE, Dickfeld T, Saliaris A, et al. (2014) Cardiac sarcoidosis: electrophysiological outcomes on long-term followup and the role of the implantable cardioverter-defibrillator. J Cardiovasc Electrophysiol 25: 171-176. Link: https://bit.ly/3rL8NKN

208. Kron J, Sauer W, Schuller J, Bogun F, Crawford T, et al. (2013) Efficacy and safety of implantable cardiac defibrillators for treatment of ventricular arrhythmias in patients with cardiac sarcoidosis. Europace 15: 347-354 Link: https://bit.ly/3DE5d7

209. Takenaka S, Kobayashi Y, Nagai T, Kato Y, Komoriyama H, et al. (2021) Applicability of the AHA/ACC/HRS Guideline for Implantable Cardioverter Defibrillator Implantation in Japanese Patients With Cardiac Sarcoidosis. JACC Clin Electrophysiol. Link: https://bit.ly/3y7MbVX

210. Sugisaki K, Yamaguchi T, Nagai S, Ohmiti M, Takenaka S, et al. (2003) Clinical characteristics of 195 Japanese sarcoidosis patients treated with oral corticosteroids. Sarcoidosis Vasc Diffuse Lung Dis 20: 222-226. Link: https://bit.ly/3EHDi8a

211. Yodogawa K, Seino Y, Ohara T, Takayama H, Katoh T, et al. (2011) Effect of corticosteroid therapy on ventricular arrhythmias in patients with cardiac sarcoidosis. Ann Noninvasive Electrocardiol 16: 140-147. Link: https://bit.ly/3oEfTys

212. Yodogawa K, Seino Y, Shiomura R, Takahashi K, Tsuboi I, et al. (2013) Recovery of atrioventricular block following steroid therapy in patients with cardiac sarcoidosis. J Cardiol. Link: https://bit.ly/3pCqyt7

213. Kaida T, Inomata T, Minami Y, Yazaki M, Fujita T, et al. (2018) Importance of Early Diagnosis of Cardiac Sarcoidosis in Patients with Complete Atrioventricular Block. Int Heart J 59: 772-778. Link: https://bit.ly/3DJVv3G

214. Nabeta T, Hara M, Naruke T, Maemura K, Oki T, et al. (2021) Clinica valuables related to resolution of complete or advanced atrioventricular block after steroid therapy in patients with cardiac sarcoidosis. J Arrhythm 37: 1093-1100. Link: https://bit.ly/3GqcWYC

215. Sadek MM, Yung D, Birnie DH, Beanlands RS, Nery PB (2013) Corticosteroid therapy for cardiac sarcoidosis: a systematic review. Can J Cardiol 29 : 1034-1041. Link: https://bit.ly/3rT7KIG

Citation: Lynch III JP, Fishbein MC, Bradfield JS, Belperio JA (2021) Cardiac involvement in sarcoidosis: Evolving concepts in diagnosis and treatment. J Cardiovasc Med Cardiol 8(4): 079-102. DOI: https://dx.doi.org/10.17352/2455-2976.000175 
216. Pierre-Louis B, Prasad A, Frishman WH (2009) Cardiac manifestations of sarcoidosis and therapeutic options. Cardiol Rev 17: 153-158. Link: https://bit.ly/3rPTdxy

217. Baughman R, Lower EE (1999) A clinical approach to the use of methotrexate for sarcoidosis. Thorax 54: 742-746. Link: https://bit.ly/3yb9TAt

218. Muller-Quernheim J, Kienast K, Held M, Pfeifer S, Costabel U (1999) Treatment of chronic sarcoidosis with an azathioprine/prednisolone regimen. Eur Respir J 14: 1117-1122. Link: https://bit.ly/31E8AOR

219. Lazar CA, Culver DA (2010) Treatment of sarcoidosis. Semin Respir Crit Care Med 31: 501-518. Link: https://bit.ly/3IBXvyj

220. Demeter SL (1988) Myocardial sarcoidosis unresponsive to steroids. Treatment with cyclophosphamide. Chest 94: 202-203. Link: https://bit.ly/3DxaGgk

221. Barnabe C, McMeekin J, Howarth A, Martin L (2008) Successful treatment of cardiac sarcoidosis with infliximab. J Rheumatol 35: 1686-1687. Link: https://bit.ly/3IB1N94

222. Vorselaars ADM, Wuyts WA, Vorselaars VMM, Zanen P, Deneer VHM, et al. (2013) Methotrexate vs azathioprine in second-line therapy of sarcoidosis Chest 144: 805-812. Link: https://bit.ly/3dyWfOJ

223. Baughman RP, Lower EE (2004) Leflunomide for chronic sarcoidosis Sarcoidosis Vasc Diffuse Lung Dis 21: 43-48. Link: https://bit.ly/3IKOae0

224. Sahoo DH, Bandyopadhyay D, Xu M, Pearson K, Parambil JG, et al. (2011) Effectiveness and safety of leflunomide for pulmonary and extrapulmonary sarcoidosis. Eur Respir J 38: 1145-1150. Link: https://bit.ly/3DECcsq

225. Brill AK, Ott SR, Geiser T (2013) Effect and safety of mycophenolate mofetil in chronic pulmonary sarcoidosis: a retrospective study. Respiration 86 : 376-383. Link: https://bit.ly/3ozLWzS

226. Bitoun S, Bouvry D, Borie R, Mahevas M, Sacre K, et al. (2016) Treatment of neurosarcoidosis: A comparative study of methotrexate and mycophenolate mofetil. Neurology 87: 2517-2521. Link: https://bit.ly/3dz8xpP

227. Stievenart J, Le Guenno G, Ruivard M, Rieu V, Andre M, et al. (2021) Case Report: TNF-alpha Antagonists Are an Effective Therapy in Cardiac Sarcoidosis. Front Cardiovasc Med 8: 676407. Link: https://bit.ly/3IKOdGI

228. Chung ES, Packer M, Lo KH, Fasanmade AA, Willerson JT, et al. (2003) Randomized, double-blind, placebo-controlled, pilot trial of infliximab, a chimeric monoclonal antibody to tumor necrosis factor-alpha, in patients with moderate-to-severe heart failure: results of the anti-TNF Therapy Against Congestive Heart Failure (ATTACH) trial. Circulation 107: 31333140. Link: https://bit.ly/3rX4egi

229. Mann DL, McMurray JJ, Packer M, Swedberg K, Borer JS, et al (2004) Targeted anticytokine therapy in patients with chronic heart failure: results of the Randomized Etanercept Worldwide Evaluation (RENEWAL) Circulation 109: 1594-1602. Link: https://bit.ly/3EGoRkv

230. Vorselaars $A D$, Crommelin HA, Deneer VH, Meek B, Claessen AM, et al. (2015) Effectiveness of infliximab in refractory FDG PET-positive sarcoidosis. Eur Respir J 46: 175-185. Link: https://bit.ly/3oBOEVk

231. Rosenthal DG, Parwani P, Murray TO, Petek BJ, Benn BS, et al. (2019) LongTerm Corticosteroid-Sparing Immunosuppression for Cardiac Sarcoidosis. J Am Heart Assoc 8: e010952. Link: https://bit.ly/31JTs22

232. Gelfand JM, Bradshaw MJ, Stern BJ, Clifford DB, Wang Y, et al. (2017) Infliximab for the treatment of CNS sarcoidosis: A multi-institutional series. Neurology 89: 2092-2100. Link: https://bit.ly/3rN9vae

233. Milman N, Graudal N, Loft A, Mortensen J, Larsen J, et al. (2012) Effect of the TNF-alpha inhibitor adalimumab in patients with recalcitrant sarcoidosis: a prospective observational study using FDG-PET. Clin Respir J 6: 238-247. Link: https://bit.ly/3EL2WZK
234. Jamilloux Y, Cohen-Aubart F, Chapelon-Abric C, Maucort-Boulch D, Marquet $A$, et al. (2017) Efficacy and safety of tumor necrosis factor antagonists in refractory sarcoidosis: A multicenter study of 132 patients. Semin Arthritis Rheum 47: 288-294. Link: https://bit.ly/3EGngLs

235. Utz JP, Limper AH, Kalra S, Specks U, Scott JP, et al. (2003) Etanercept for the treatment of stage II and III progressive pulmonary sarcoidosis. Chest 124: 177-185. Link: https://bit.ly/3ymwwCt

236. Baughman RP, Lower EE, Bradley DA, Raymond LA, Kaufman A (2005) Etanercept for refractory ocular sarcoidosis: results of a double-blind randomized trial. Chest 128: 1062-1047. Link: https://bit.ly/3oEgKj4

237. Crommelin $H A$, van der Burg $L M$, Vorselaars $A D$, Drent $M$, van Moorsel $\mathrm{CH}$, et al. (2016) Efficacy of adalimumab in sarcoidosis patients who developed intolerance to infliximab. Respir Med 115: 72-77. Link: https://bit.ly/3GoYy2M

238. Bomprezzi R, Pati S, Chansakul C, Vollmer T (2010) A case of neurosarcoidosis successfully treated with rituximab. Neurology 75: 568570. Link: https://bit.ly/307xOEr

239. Krause ML, Cooper LT, Chareonthaitawee P, Amin S (2016) Successful use of rituximab in refractory cardiac sarcoidosis. Rheumatology (Oxford) 55 : 189-191. Link: https://bit.ly/3pEjgVI

240. Damsky W, Thakral D, McGeary MK, Leventhal J, Galan A, et al. (2020) Janus kinase inhibition induces disease remission in cutaneous sarcoidosis and granuloma annulare. J Am Acad Dermatol 82: 612-621. Link: https://bit.ly/3dBjcjL

241. Rotenberg C, Besnard V, Brillet PY, Giraudier S, Nunes H, et al. (2018) Dramatic response of refractory sarcoidosis under ruxolitinib in a patient with associated JAK2-mutated polycythemia. Eur Respir J 52. Link: https://bit.ly/3pl9gL0

242. Lynch III J, Hunninghake G (1992) Sarcoidosis. In: Lichtenstein LM, Fauci AS, eds. Current Therapy in Allergy, Immunology and Rheumatology. Philadelphia: B.C.Decker 243-251.

243. Lynch III JP, Kazerooni EA, Gay SE (1997) Pulmonary sarcoidosis. Clin Chest Med 18: 755-785. Link: https://bit.ly/31GfK4O

244. Lynch III J, Baughman R, Sharma O (1998) Extrapulmonary sarcoidosis. Semin Respir Infect 13: 229-254. Link: https://bit.ly/3lwhNcx

245. Lynch JP 3rd, Ma YL, Koss MN, White ES (2007) Pulmonary sarcoidosis. Semin Respir Crit Care Med 28: 53-74. Link: https://bit.ly/3Gn8Dgw

246. Lynch JP 3rd, McCune WJ (1997) Immunosuppressive and cytotoxic pharmacotherapy for pulmonary disorders. Am J Respir Crit Care Med 155: 395-420. Link: https://bit.ly/3IBYgHF

247. Wang T, Weigt SS, Belperio JA, Lynch JP (2011) Immunosuppressive and cytotoxic therapy: pharmacology, toxicities, and monitoring. Semin Respir Crit Care Med 32: 346-370. Link: https://bit.ly/3dAMxLq

248. Jain A, Starek PJ, Delany DL (1990) Ventricular tachycardia and ventricular aneurysm due to unrecognized sarcoidosis. Clin Cardiol 13: 738-740. Link: https://bit.ly/3pYhsqT

249. Lull RJ, Dunn BE, Gregoratos G, Cox WA, Fisher GW (1972) Ventricular aneurysm due to cardiac sarcoidosis with surgical cure of refractory ventricular tachycardia. Am J Cardiol 30: 282-287. Link: https://bit.ly/3rPXZeu

250. Harris IM, Guarino R (1994) Cardiac sarcoidosis: a new approach to treatment. Cardiovasc Surg 2: 420-422. Link: https://bit.ly/3EHetsN

251. Perkel D, Czer LS, Morrissey RP, Ruzza A, Rafiei M, et al. (2013) Heart transplantation for end-stage heart failure due to cardiac sarcoidosis. Transplant Proc 45: 2384-2386. Link: https://bit.ly/3IKORUE 
252. Chang TI, Chi NH, Chou NK, Tsao Cl, Yu HY, et al. (2012) Isolated cardiac sarcoidosis in heart transplantation. Transplant Proc 44: 903-906. Link: https://bit.ly/3INRUeD

253. Zaidi AR, Zaidi A, Vaitkus PT (2007) Outcome of heart transplantation in patients with sarcoid cardiomyopathy. J Heart Lung Transplant 26: 714717. Link: https://bit.ly/3oCIKV9

254. Milman N, Andersen CB, Mortensen SA, Sander K (2008) Cardiac sarcoidosis and heart transplantation: a report of four consecutive patients. Sarcoidosis Vasc Diffuse Lung Dis 25: 51-59. Link: https://bit.ly/3096Mg5

255. Donsky AS, Escobar J, Capehart J, Roberts WC (2002) Heart transplantation for undiagnosed cardiac sarcoidosis. Am J Cardiol 89: 1447-1450.

256. Akashi H, Kato TS, Takayama H, Naka Y, Farr M, et al. (2012) Outcome of patients with cardiac sarcoidosis undergoing cardiac transplantation-single-center retrospective analysis. J Cardiol 60: 407-410. Link: https://bit.ly/3oB4IXs

257. Genovese L, Dey AK, Cole RT, Cooper LB, Desai S, et al. (2021) Fulminant cardiogenic shock due to cardiac sarcoidosis. J Community Hosp Intern Med Perspect 11: 673-677. Link: https://bit.ly/3GwJQXH

258. Makhdumi M, Assar MD, Meyer DM, Roberts WC (2021) Cardiac sarcoidosis diagnosed after orthotopic heart transplantation and clinically mimicking arrhythmogenic right ventricular cardiomyopathy. Cardiovasc Pathol 56 107390. Link: https://bit.ly/3oB4NKK

259. Bobbio E, Bjorkenstam M, Nwaru BI, Giallauria F, Hessman E, et al. (2021) Short- and long-term outcomes after heart transplantation in cardiac sarcoidosis and giant-cell myocarditis: a systematic review and metaanalysis. Clin Res Cardiol. Link: https://bit.ly/3GqSqHb

260. Rosenthal DG, Anderson ME, Petek BJ, Arnett DM, Bravo PE, et al. (2018) Invasive Hemodynamics and Rejection Rates in Patients With Cardiac Sarcoidosis After Heart Transplantation. Can J Cardiol 34: 978-982. Link: https://bit.ly/3IPXcGp

261. Khan R, Tweedie EJ, Pflugfelder PW, White JA (2010) Cardiac sarcoid in a heart transplant recipient: detection with cardiac magnetic resonance imaging. Transplant Proc 42: 1976-1978. Link: https://bit.ly/3y8f4kM

262. Luk A, Lee A, Ahn E, Soor GS, Ross HJ, et al. (2010) Cardiac sarcoidosis: recurrent disease in a heart transplant patient following pulmonary tuberculosis infection. Can J Cardiol 26: e273-e275. Link: https://bit.ly/31KS8w6

263. Yager JE, Hernandez AF, Steenbergen C, Persing B , Russell SD ,et al. (2005) Recurrence of cardiac sarcoidosis in a heart transplant recipient. J Heart Lung Transplant 24: 1988-1990. Link: https://bit.ly/3EDCQYd

264. Wiltshire S, Nadel J, Meredith T, Iglesias CK, Qiu MR, et al. (2021) Twice Bitten, Thrice Shy: A Case of Recurrent Isolated Cardiac Sarcoidosis in the Transplanted Heart. JACC Case Rep 3: 427-432. Link: https://bit.ly/307W7SK

265. Oni AA, Hershberger RE, Norman DJ, Ray J, Hovaguimian $H$, et al. (1992) Recurrence of sarcoidosis in a cardiac allograft: control with augmented corticosteroids. J Heart Lung Transplant 11: 367-369. Link: https://bit.ly/31NeMnd

\section{Discover a bigger Impact and Visibility of your article publication with}

\section{Peertechz Publications}

\section{Highlights}

* Signatory publisher of ORCID

* Signatory Publisher of DORA (San Francisco Declaration on Research Assessment)

* Articles archived in worlds' renowned service providers such as Portico, CNKI, AGRIS, TDNet, Base (Bielefeld University Library), CrossRef, Scilit, J-Gate etc.

* Journals indexed in ICMJE, SHERPA/ROMEO, Google Scholar etc.

* OAl-PMH (Open Archives Initiative Protocol for Metadata Harvesting)

* Dedicated Editorial Board for every journal

* Accurate and rapid peer-review process

* Increased citations of published articles through promotions

* Reduced timeline for article publication

Submit your articles and experience a new surge in publication services (https://www.peertechz.com/submission).

Peertechz journals wishes everlasting success in your every endeavours. 